\title{
COLLECTIVE CHOICE AND VOLUNTARY PROVISION OF PUBLIC GOODS
}

\author{
Dennis Epple \\ Richard Romano
}

Working Paper 7802

http://www.nber.org/papers/w7802

\author{
NATIONAL BUREAU OF ECONOMIC RESEARCH \\ 1050 Massachusetts Avenue \\ Cambridge, MA 02138 \\ July 2000
}

We thank David Figlio, Jon Hamilton, and Steve Slutsky for helpful discussions about this paper and thank the National Science Foundation and MacArthur Foundation for support. The views expressed here are the authors' and do not necessarily reflect those of the National Bureau of Economic Research.

(C) 2000 by Dennis Epple and Richard Romano. All rights reserved. Short sections of text, not to exceed two paragraphs, may be quoted without explicit permission provided that full credit, including (C) notice, is given to the source. 
Collective Choice and Voluntary Provision of Public Goods

Dennis Epple and Richard Romano

NBER Working Paper No. 7802

July 2000

JEL No. H41, D78

\begin{abstract}
Some public goods are provided entirely with private contributions, others with a mixture of public and private funding, and still others are entirely publicly funded. To explain this variation, a model of dual provision is developed that endogenizes public and private funding. Members of the economy vote over an income tax that finances public supply of the good, and they vote on whether to permit private contributions. While permitting private contributions may lead to a reduction in total provision of the good, a majority always favors permitting private contributions. Results are developed for small and large economies, and the relevance of excludability and noncongestion are investigated. Comparative statics and computational analysis demonstrate properties of equilibrium.
\end{abstract}

Dennis Epple

Graduate School of Industrial Administration

Carnegie Mellon University

Pittsburgh, PA 15213

and NBER

epple@cmu.edu
Richard Romano

Department of Economics, 203 MAT

University of Florida

Gainesville, FL 32611

romanor@dale.cba.ufl.edu 


\section{Collective Choice and Voluntary Provision of Public Goods \\ Dennis Epple and Richard Romano}

\section{Introduction}

National defense and public radio are examples of the purest of public goods. In 1990, the ratio of voluntary to total expenditure on national defense was negligible, while the non-tax share of expenditures on public radio was 53\% (Statistical Abstract 1992, Table 893, p. 555). While voluntary contributions to public radio accounted for about half of its provision, voluntary contributions to national defense were zero as a first approximation. A 1987 American Library Association survey found that although "only $22.6 \%$ of libraries reported non-tax revenues equal to $20 \%$ or more of operating expenditures ... over $9 \%$ of libraries -- all serving populations less that 100,000 -- report that over $50 \%$ of operating expenditures came from non-tax dollars (p. 2)." Instances of libraries that receive "very little tax revenue" were found as well. Among 112 U.S. art museums surveyed over the period 1986-88, private and corporate contributions accounted for $33.5 \%$ of revenues while total government support comprised $31.6 \%$, with remaining revenues from endowment earnings (17.4\%) and direct earnings (17.5\%) like entry fees (Rosett, 1991, Table 6.7, p. 142). For those museums located in the smallest $11 \%$ of metropolitan areas in the survey, the donor percentage of revenues rises to 48 and the government percentage declines to 21 (Table 6.3, p. 136). Many historic preservation societies operate with no government monies. Other public goods like basic research are associated with substantial variation in the mixture of public and private finance across purpose and time. What explains the stark variation in provision regimes?

In this paper we analyze a model of dual provision of a public good in an effort to understand better the interaction of collective and individual incentives in the provision of public 
goods. Members of the economy vote over an income tax that finances public supply of the good. They may then make unilateral contributions. We develop fairly general conditions such that equilibrium exists in this setting and examine the properties of equilibrium. We show further that allowing dual provision is the political equilibrium, i.e., that prohibiting public or private provision is never strictly majority preferred. We develop results for small (local) economies and for large economies. Positive levels of public and voluntary private provision may characterize a small economy, but dual provision fails to arise in large economies. We examine the relevance of excludability and congestion of the good for these findings.

This paper provides a bridge between the literatures on collective choice of and voluntary provision of public goods. A central concern in the voluntary provision literature has been with the extent of crowding out of voluntary contributions to the good by public provision. ${ }^{1}$ The crowding-out phenomenon is an important aspect of the present analysis, and we discuss further this literature at the appropriate points. We add to this literature by making public provision endogenous with implications for crowding out taken into account by voters in the collectivedecision process. $^{2}$

The voluminous literature entailing majority choice of provision of public goods generally ignores the possibility of concomitant voluntary provision. ${ }^{3}$ Epple and Romano (1996a,1996b), Gouveia (1997), Glomm and Ravikumar (1998), and Anderberg (1999) have

\footnotetext{
${ }^{1}$ See Warr (1983), Cornes and Sandler (1984), Bernheim (1985), Bergstrom, Blume, and Varian (1986), Andreoni (1988,1989,1990), Steinberg (1986), and Fries, Golding, and Romano (1991).

${ }^{2}$ Scharf ( 2000) also develops a model of dual provision that endogenizes voluntary and government provision, with focus on the political economy of tax incentives for giving. Her's is a two-type model where one type is elected to choose both tax rate to finance public provision and tax break to voluntary provision. Our model permits many types and emphasizes their collective choice, but of only the tax rate.

${ }^{3}$ Well known references are Barr and Davis (1966), Borcherding and Deacon (1972), Bergstrom and Goodman (1973), Bergstrom (1979), and Atkinson and Stiglitz (1980). See Ordeshook (1986) and Mueller (1989) for more references.
} 
examined public choice of a private good when private consumption is also feasible. Again we relate the present findings to this literature more thoroughly as our results unfold.

The next section describes the model. The general results are presented in Section 3. Section 4 provides computational examples and considers implications for large economies. The roles of congestion and excludability are examined in Section 5. Section 6 concludes.

\section{The Model}

Agents. The model is fairly standard. Agents in the economy have the same utility function $\mathrm{U}(\mathrm{x}, \mathrm{G})$, where $\mathrm{x}$ is the numeraire good and $\mathrm{G}$ the public good measured in units of the numeraire. $\mathrm{U}$ is increasing, twice differentiable, and strictly quasi-concave in $(x, G)$ on $\mathrm{R}_{+}{ }^{2}$. We assume the ordinary demands for $\mathrm{x}$ and $\mathrm{G}$ are both normal. Assume too that strictly positive levels of $\mathrm{x}$ and G always yield higher utility than any pair with zero of one good. Later we introduce agents who are indifferent to $\mathrm{G}$.

Agents have endowed income $y$. The economy consists of $Y$ different income types, with $\mathrm{n}^{\mathrm{y}}$ of each type. Let $\mathrm{n} \equiv \sum_{\mathrm{y}} \mathrm{n}^{\mathrm{y}}$ denote the economy's population, where sums are over all values of the indicated variable unless stated otherwise. When it is not clear by context, we will write $\mathrm{y}_{\mathrm{i}}$ to indicate a particular income, and in the case of numerical subscripts, assume $0<\mathrm{y}_{1}<$ $\mathrm{y}_{2}<\ldots<\mathrm{y}_{\mathrm{Y}}$. We make two very weak technical assumptions on the distribution of types to avoid some tedious cases and clarify below their role. As is realistic, we assume no one type constitutes a majority: $\mathrm{n}^{\mathrm{y}_{\mathrm{i}}}<.5$. We also assume without loss of genericity that there is no subset of income types, $\mathrm{Y}_{\mathrm{s}}$, such that $\frac{1}{\mathrm{n}_{\mathrm{y} \in \mathrm{Y}_{\mathrm{s}}}} \mathrm{n}^{\mathrm{y}}=.5$. This implies, for example, that median income is unique. Let $\mathrm{g}^{\mathrm{d}}(\mathrm{y}) \equiv \operatorname{Argmax}_{\mathrm{g}} \mathrm{U}(\mathrm{y}-\mathrm{g}, \mathrm{g})$ denote the ordinary demand for the public good, which will be useful later. Our assumptions on $\mathrm{U}$ imply $\mathrm{g}^{\mathrm{d}}(\mathrm{y})$ is positive, continuous, and differentiable, and the normality assumptions imply: 


$$
g^{d^{\prime}}(y) \in(0,1)
$$

Public Good Provision and Equilibrium. Public provision of $\mathrm{G}$ is financed by a proportional income tax denoted $t$. The majority preferred $t$ is first selected, and then agents may contribute unilaterally to the total. Below we show that allowing dual provision is also the political equilibrium. Voluntary contributions make up a (simultaneous-move) Nash equilibrium given t, and agents anticipate the voluntary contribution equilibrium when voting over public provision. Budget balance implies that

$$
\mathrm{G}=\operatorname{tn} \overline{\mathrm{y}}+\sum_{\mathrm{y}} \mathrm{n}^{\mathrm{y}} \mathrm{g}^{\mathrm{y}}
$$

where $\overline{\mathrm{y}}$ is mean income and $\mathrm{g}^{\mathrm{y}} \geq 0$ denotes the voluntary contribution of agent with income $\mathrm{y}$.

For given $\mathrm{t}, \mathrm{G}_{-\mathrm{y}_{\mathrm{i}}}$, and any $\mathrm{y}=\mathrm{y}_{\mathrm{i}}$,

$$
g^{y_{i}}=\operatorname{Argmax}_{g 20} U\left(y_{i}(1-t)-g, g+G_{-y_{i}}\right)
$$

where $G_{-y_{i}} \equiv G-g^{y_{i}}$ denotes provision other than the voluntary contribution of one agent with income $y_{i}$. Hence, $g^{y_{i}}$ satisfies

$$
\begin{gathered}
-U_{x}+U_{G} \leq 0 \\
\left(-U_{x}+U_{G}\right) g^{y_{i}}=0 \\
g^{y_{i}} \geq 0
\end{gathered}
$$

where the subscripts denote partial derivatives and utility is evaluated as in (3). For any t, voluntary contribution equilibrium exists, is uniqueness, and exhibits symmetry within income types (see Bergstrom, et. al., 1986). Results for the two-stage equilibrium we study are developed in the next section. 


\section{Analysis and Results}

A Voter's Preferences. To develop equilibrium properties, we follow the same analytical strategy employed in Epple and Romano (1996a,1996b). We find a type-y agent's preferences $\operatorname{over}\left(t, G_{-y}\right)$ that incorporate the agent's own second-stage behavior, but that treat $\left(t, G_{-y}\right)$, hence other agents' choices and characteristics (incomes), as exogenous. The nature of these preferences alone may allow us to establish existence of equilibrium and identify the pivotal voter. The characterization of equilibrium is then completed by constraining choices to be consistent with all agents' choices and introducing the implied budget constraint. In particular, agents anticipate how choice of the tax rate and thus public expenditure will affect second-stage private contributions.

To derive the preference mapping, let $\hat{\mathrm{g}}^{\mathrm{y}}\left(\mathrm{t}, \mathrm{G}_{-\mathrm{y}}\right)$ denote the function that solves (4) for $\operatorname{arbitrary}\left(\mathrm{t}, \mathrm{G}_{-\mathrm{y}}\right)$. Using that $\frac{\mathrm{U}_{\mathrm{G}}\left(\mathrm{y}-\mathrm{g}^{\mathrm{d}}, \mathrm{g}^{\mathrm{d}}\right)}{\mathrm{U}_{\mathrm{x}}(\cdot)}=1$ defines $\mathrm{g}^{\mathrm{d}}$ and manipulating the arguments in (4), one obtains:

$$
\hat{\mathrm{g}}^{\mathrm{y}}\left(\mathrm{t}, \mathrm{G}_{-\mathrm{y}}\right)=\operatorname{Max}\left[\mathrm{g}^{\mathrm{d}}\left(\mathrm{y}(1-\mathrm{t})+\mathrm{G}_{-\mathrm{y}}\right)-\mathrm{G}_{-\mathrm{y}}, 0\right]
$$

Thus $\hat{\mathrm{g}}^{\mathrm{y}}$ is the contribution made by type $\mathrm{y}$ when the tax rate is $\mathrm{t}$ and others contribute $\mathrm{G}_{-\mathrm{y}}$. One can then substitute $\hat{\mathrm{g}}^{\mathrm{y}}$ into the utility function in (3) and obtain indirect utility over $\left(\mathrm{t}, \mathrm{G}_{-\mathrm{y}}\right)$. It is much more convenient, however, to work with indirect utility over $(\mathrm{t}, \mathrm{G})$. Using that $\mathrm{G}_{-\mathrm{y}} \equiv \mathrm{G}-\mathrm{g}^{\mathrm{y}}$, find $\tilde{\mathrm{g}}^{\mathrm{y}}(\mathrm{t}, \mathrm{G})$ as the fixed point of

$$
\tilde{\mathrm{g}}^{\mathrm{y}}=\hat{\mathrm{g}}^{\mathrm{y}}\left(\mathrm{t}, \mathrm{G}-\tilde{\mathrm{g}}^{\mathrm{y}}\right) \text {. }
$$

Function $\tilde{\mathrm{g}}^{\mathrm{y}}(\cdot)$ gives the equilibrium contribution by type $\mathrm{y}$ when the tax rate is that is consistent with total provision of amount G. Then substitute into the utility function and define 
indirect utility:

$$
\mathrm{V}(\mathrm{t}, \mathrm{G}) \equiv \mathrm{U}\left(\mathrm{y}(1-\mathrm{t})-\tilde{\mathrm{g}}^{\mathrm{y}}(\mathrm{t}, \mathrm{G}), \mathrm{G}\right)
$$

We now show that the latter preference mapping appears as shown in Figure 1, beginning with a lemma.

Lemma 1. For type-y agent, there is a locus of positive values $\tilde{\mathfrak{t}}(\mathrm{G}, \mathrm{y})$ defined by:

$\mathrm{g}^{\mathrm{d}}(\mathrm{y}(1-\tilde{\mathrm{t}})+\mathrm{G})=\mathrm{G}$; such that for $\mathrm{t} \geq(<) \tilde{\mathrm{t}}, \tilde{\mathrm{g}}^{\mathrm{y}}=(>) 0$. Also, $\frac{\partial \tilde{\mathrm{t}}}{\partial \mathrm{G}}<0$ and $\frac{\partial \tilde{\mathrm{t}}}{\partial \mathrm{y}}>0$.

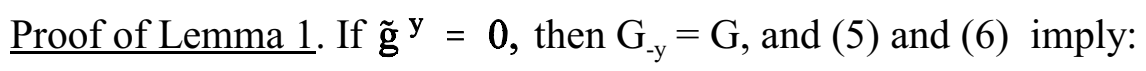

$$
g^{d}(y(1-t)+G) \leq G \text { for } \tilde{g}^{y}=0
$$

If $\tilde{g}^{y}>0$, then $g^{d}\left(y(1-t)+G_{-y}\right)=G$ by (5) and (6). Using (1) then:

$$
\mathrm{g}^{\mathrm{d}}(\mathrm{y}(1-\mathrm{t})+\mathrm{G})>\mathrm{G} \text { for } \tilde{\mathrm{g}}^{\mathrm{y}}>0
$$

Using (1), (L1.I) and (L1.ii) then imply the results in the first sentence of Lemma 1. The results in the second sentence follow by differentiation of $g^{d}(y(1-\tilde{t})+G)=G$, again using (1).

Graphically, in Figure 1, above the $\tilde{\mathrm{t}}$ locus $\mathrm{G}$ is high enough and after-tax income is low enough that the agent would not make a voluntary contribution. ${ }^{4}$ Below the $\tilde{\mathrm{t}}$ locus, where the agent makes a voluntary contribution, (5) indicates that $\mathrm{G}$ must equal the agent's ordinary demand if he had income (1-t)y $+G_{-y}$. As an agent's income rises, the $\tilde{\mathrm{t}}$ locus then shifts out because of the normality of demand. Regarding the indifference curves drawn in Figure 1, we

${ }^{4}$ Neither will the agent make a voluntary contribution for any $(t, G)$ to the right of the G-axis intercept of $\tilde{\mathbf{t}}$. This can be proved following our proof by redefining $\tilde{t}$ to include the $\mathrm{G}$ axis beyond the intercept. 
have:

Lemma 2. Below the $\tilde{\mathrm{t}}$ locus, an agent's indifference curves $\mathrm{V}(\mathrm{t}, \mathrm{G})=\mathrm{K}$ (a constant) are vertical in the $(G, t)$ plane. Above the $\tilde{\mathfrak{t}}$ locus, the indifference curves are upward sloping.

Proof of Lemma 2. Using (7) and differentiating $V(t, G)=K$, one obtains:

$$
\left.\frac{\mathrm{dt}}{\mathrm{dG}}\right|_{\mathrm{V}=\mathrm{K}}=\frac{\mathrm{U}_{\mathrm{G}}-\mathrm{U}_{\mathrm{x}} \partial \tilde{\mathrm{g}}^{\mathrm{y} / \partial \mathrm{G}}}{\mathrm{U}_{\mathrm{x}} \cdot\left(\mathrm{y}+\partial \tilde{g}^{\mathrm{y}} / \partial \mathrm{t}\right)} .
$$

Above the $\tilde{\mathrm{t}}$ locus, $\tilde{\mathrm{g}}^{\mathrm{y}}=0$, its partial derivatives vanish, and

$$
\left.\frac{\mathrm{dt}}{\mathrm{dG}}\right|_{\mathrm{V}=\mathrm{K}}=\frac{\mathrm{U}_{\mathrm{G}}}{\mathrm{yU}_{\mathrm{x}}}>0 \text { for } \mathrm{t}>\tilde{\mathrm{t}}(\mathrm{G}, \mathrm{y})
$$

Below the $\tilde{\mathrm{t}}$ locus, $\tilde{\mathrm{g}}^{\mathrm{y}}>0$. Using (5) and (6) then:

$$
\frac{\partial \tilde{\mathrm{g}}^{\mathrm{y}}}{\partial \mathrm{t}}=-\mathrm{y} \text { and } \frac{\partial \tilde{\mathrm{g}}^{\mathrm{y}}}{\partial \mathrm{G}}=-\frac{1-\mathrm{g} \mathrm{d}^{\prime}}{\mathrm{g}^{\mathrm{d}} /} \text { for } \tilde{\mathrm{g}}^{\mathrm{y}}>0
$$

implying:

$$
\left.\frac{\mathrm{dt}}{\mathrm{dG}}\right|_{\mathrm{V}=\mathrm{K}}=\infty \text { for } \mathrm{t}<\tilde{\mathrm{t}}(\mathrm{G}, \mathrm{y}) .
$$

The vertical segment of an agent's indifference curve corresponds to an individual-level version of Warr's (1983) neutrality or "complete crowding out" result. For given G, as t rises, utility is unchanged as long as the agent is making a contribution. The agent reduces his 
contribution by the amount of the increased tax cost. If utility were to decrease as $t$ increases, this would contradict the agent's continued giving, since the agent would prefer to substitute the numeraire for $\mathrm{G}$. As $\mathrm{t}$ rises above $\tilde{\mathrm{t}}$ and the agent ceases to contribute, utility does, of course, decline as $t$ increases. Our quasiconcavity assumption on $\mathrm{U}$ implies the indifference curves above $\tilde{\mathrm{t}}$ are concave as drawn, but this is irrelevant to the results that follow.

Now we place a further restriction on preferences. Recalling (L2.ii) in Lemma 2, let $\mathrm{S}(\mathrm{y}, \mathrm{t}, \mathrm{G}) \equiv \mathrm{U}_{\mathrm{G}}(\mathrm{y}(1-\mathrm{t}), \mathrm{G}) /\left[\mathrm{y} \mathrm{U}_{\mathrm{x}}(\cdot)\right]$ denote the slope of an indifference curve above the $\tilde{\mathrm{t}}$ locus. We assume that either:

$$
\begin{aligned}
\partial \mathrm{S} / \partial \mathrm{y} \geq & 0 \forall(\mathrm{y}, \mathrm{G}, \mathrm{t}) \\
& \text { or } \\
\partial \mathrm{S} / \partial \mathrm{y} \leq & 0 \forall(\mathrm{S}, \mathrm{G}, \mathrm{t})
\end{aligned}
$$

SRI stands for "slope rising in income" and SDI for "slope declining in income." Panel A of Figure 2 depicts SRI and Panel B depicts SDI. Using that the $\tilde{\mathrm{t}}$ locus shifts out with income (Lemma 1), it is easy to see that indifference curves of any two agents can cross at most once under SRI, but may cross twice under SDI.

Whether SRI or SDI is the more appropriate assumption depends on the relative magnitudes of the price and income elasticities of the ordinary demand for G. The marginal willingness to pay for public provision rises with income since $\mathrm{G}$ is a normal good, but this is countered by the increased tax price. Kenny (1978) has shown that SRI results if the income elasticity of demand exceeds the (absolute value of the) price elasticity, and SDI holds in the reverse case. ${ }^{5}$ For example, the CES utility function used later in our computations:

\footnotetext{
${ }^{5}$ We adapt Kenny's analysis to our specific problem in an appendix available on request.
} 
$\mathrm{U}=\left[\mathrm{ax}^{\alpha}+(1-\mathrm{a}) \mathrm{G}^{\alpha}\right]^{\frac{1}{\alpha}}, \alpha<1, \mathrm{a} \in(0,1)$; has SRI if $\alpha<0$ and SDI if $\alpha \in(0,1)$. Demand for

$\mathrm{G}$ is inelastic in the former case and elastic in the latter case, and the CES utility function has unitary income elasticity. Bergstrom and Goodman's (1973) study of the demand for public services supports an assumption of SRI for police protection, public parks, and general (noneducational) municipal expenditures. On the other hand, an assumption of SDI may be more appropriate for public transportation.

The Public-Good Budget Constraint. As discussed below, key results can be obtained with virtually no restrictions on feasible $(\mathrm{t}, \mathrm{G})$ pairs. Nevertheless, we think it clearer to now develop the properties of the public-good budget constraint. Let $\tilde{G}(t)$ denote this constraint, with domain $\mathrm{t} \in[0,1]$, and which satisfies (2) and (6), the latter for all types. Hence, $\tilde{\mathrm{G}}$ is the fixed point:

$$
\tilde{\mathrm{G}}=\mathrm{nty}+\sum_{\mathrm{y} \geq \mathrm{y}_{\mathrm{c}}(\tilde{\mathrm{G}}, \mathrm{t})} \mathrm{n}^{\mathrm{y}} \tilde{\mathrm{g}}^{\mathrm{y}}(\mathrm{t}, \tilde{\mathrm{G}})
$$

where $\mathrm{y}_{\mathrm{c}}(\mathrm{G}, \mathrm{t})$ is the minimum-income agent that makes a voluntary contribution given $(\mathrm{G}, \mathrm{t})$. $\tilde{G}(t)$ will be as shown in either Figure $3 A$ or $3 B$ :

Lemma 3. $\tilde{G}(\mathrm{t})$ :

a. is a continuous function;

b. is greater than $n t \bar{y}$ on $\left[0, t^{*}\right]$ for some $t^{*}<1$ and equal tonty on $\left[\mathrm{t}^{*}, 1\right]$;

c. is differentiable except at $Y$ or fewer points satisfying $t=\tilde{t}\left(\tilde{G}(t), y_{i}\right)$ for some income $(s) y_{i}$, with right-side derivative:

$$
\tilde{G}^{\prime}(t)^{(+)}=\frac{n \bar{y}-\sum_{y \geq y_{c}(\tilde{G}(t), t)} n^{y_{y}}}{1+\sum_{y \geq y_{c}(\tilde{G}(t), t)} n^{y}\left(\frac{1-g^{d^{\prime}}\left(y(1-t)+\tilde{G}-\tilde{g}^{y}\right)}{g^{d^{\prime}}(\cdot)}\right)} ;
$$


d. is upward sloping, except sometimes it is initially flat on $\left[0, \mathrm{t}^{* *}\right]$ for some $\mathrm{t}^{* *} \leq \mathrm{t}^{*}$;

e. has $\tilde{\mathrm{G}}^{\prime}(\mathrm{t})^{(+)}>\tilde{\mathrm{G}}^{\prime}(\mathrm{t})^{(-)}$at all kinks;

f. and is piecewise linear if $\mathrm{g}^{\mathrm{d}}(\cdot)$ has income elasticity of one.

Proof of Lemma 3 is in the appendix. The economically important properties of $\tilde{G}$ are intuitive. Total provision of the public good exceeds public expenditure unless $t$ and $\mathrm{G}$ are high enough that there are no voluntary contributions. If at $\mathrm{t}=0$ all types make a voluntary contribution (see Figure 3A), then $\mathrm{G}$ is unchanged as $\mathrm{t}$ rises until the poorest types' effective income, $y_{1}(1-t)+G_{-y_{1}}$, becomes low enough that they cease to contribute (see (5)). This constancy of G is an aspect of the well-known neutrality result (Warr(1983), Bernheim(1986), Bergstrom, et. al.(1986)). All types will contribute at low t only if the range of incomes and the number of agents are sufficiently small (Bergstrom, et. al. (1986), Andreoni (1988), Fries, et.al. (1991)). When some are not contributing voluntarily, then $\mathrm{G}$ increases with $\mathrm{t}$ as noncontributors are forced to increase their expenditure on G, though contributors now decrease their total expenditure (tax and voluntary). For positive contributors, $\frac{\mathrm{d}[\mathrm{ty}+\tilde{\mathrm{g}}(\mathrm{t}, \tilde{\mathrm{G}}(\mathrm{t}))]}{\mathrm{dt}}=\mathrm{y}+\frac{\partial \tilde{\mathrm{g}}}{\partial \mathrm{t}}+\frac{\partial \tilde{\mathrm{g}}}{\partial \mathrm{G}} \tilde{\mathrm{G}}^{\prime}=-\frac{1-\mathrm{g}^{\mathrm{d}^{\prime}}}{\mathrm{g}^{\mathrm{d}^{\prime}}} \tilde{\mathrm{G}}^{\prime}<0$, the latter equality using (L2.iii). The inequality is implied by (1) and that $\tilde{\mathrm{G}}^{\prime}>0$. $\tilde{\mathrm{G}}^{\prime}>0$ is implied by the latter equality. If $\tilde{\mathrm{G}}^{\prime} \leq 0$, then voluntary contributors would weakly increase their total contributions with $\mathrm{t}$ (tax plus voluntary), contradicting $\tilde{\mathrm{G}}^{\prime} \leq 0$ (since noncontributors necessarily "give" more). ${ }^{6}$ As we move up $\tilde{\mathrm{G}}$, kinks arise when types cease to contribute, and $\tilde{\mathrm{G}}$ increases more rapidly as neutralization effects vanish.

Properties of Voting Equilibrium. If voting equilibrium exists, it must be a majority preferred

\footnotetext{
${ }^{6}$ The Proof of Lemma 3d shows that $\tilde{\mathrm{G}}^{\prime}>0$ more directly.
} 
pair $(\mathrm{t}, \tilde{\mathrm{G}}(\mathrm{t}))$. Before we examine existence, it is useful to show:

Proposition 1. An equilibrium point corresponds to a local maximum of $\mathrm{V}(\mathrm{t}, \tilde{\mathrm{G}}(\mathrm{t}))$ for some "pivotal" type $\mathrm{y}_{\mathrm{p}}$. The pivotal type is a noncontributor in equilibrium.

Proof. If no one is at a local maximum, then every type prefers some marginal change in $\mathrm{t}$. Since no subset of types makes up exactly one-half of the population, a strict majority must prefer some marginal change in t. $^{7}$ To prove the second statement, first recall from Lemma 2 that if an agent is making a voluntary contribution, then his indifference curve in the (G,t) plane is locally vertical (and with utility increasing in G). If $\tilde{G}(t)$ is upward sloping, it is then impossible for the agent to be at a local maximum. The only possibility of having a contributor at a local maximum is to be at a point along the vertical portion of $\tilde{\mathrm{G}}(\mathrm{t})$ in a case of $\tilde{\mathrm{G}}(\mathrm{t})$ like that depicted in Figure 3A. We now argue, however, that it is impossible to have equilibrium along the vertical segment of $\tilde{G}(t)$, because any such point would be defeated by a strict majority that prefer any point on $\tilde{G}(t)$ marginally above the vertical segment (like point $\mathrm{Z}$ in Figure 3A). All types with income above the poorest type $\mathrm{y}_{1}$ have indifference curves that follow the vertical segment of $\tilde{\mathrm{G}}(\mathrm{t})$ and continue to be vertical beyond the first kink of $\tilde{\mathrm{G}}(\mathrm{t})$, because that kink must occur where the poorest type ceases to contribute. Hence, all types with income exceeding $\mathrm{y}_{1}$ prefer a marginal increase in $\mathrm{t}$ above the kink, i.e., prefer a point like $\mathrm{Z}$ in Figure 3A. Since no single income-type makes up a majority, then there cannot be an equilibrium along the vertical segment of $\tilde{\mathrm{G}}(\mathrm{t})$. It follows that the pivotal voter must be a noncontributor in an equilibrium.

That equilibrium must be at some agent's own local maximum is fairly evident and

\footnotetext{
${ }^{7}$ The result need not hold if we allow a subset of types to equal one-half the population. This would introduce the possibility of a genre of multiple equilibria.
} 
requires little discussion (but see footnote 7). We refer to this agent as pivotal because his choice will be balanced by two coalitions, one that prefers moving up $\tilde{G}(t)$ and the other down (unless at a boundary of $\tilde{G}(t))$. The nature of these two coalitions is developed in Proposition 2.

Underlying the second part of Proposition 1 is that a contributor always favors a marginal tax increase that increases supply of $G$ that is exogenous to his own contribution. Hence, a contributor can never be at a local maximum, excepting in the case where $\tilde{G}(t)$ is vertical which we rule out as an equilibrium otherwise. The argument there may suggest that an economy with just one income type might have a contributor be pivotal. We show this is false as well in the section of the appendix on "kinky equilibria."

With regard to existence and the identity of the pivotal voter, we have:

Proposition 2. a. If SRI characterizes preferences, then equilibrium exists. Equilibrium must be a most preferred point on $\tilde{G}(t)$ of a median-income agent.

b. If SDI characterizes preferences, then, if equilibrium exists, it is a locally most preferred point on $\tilde{G}(t)$ of an agent with income $y_{p}$ such that: ${ }^{8}$

$$
\begin{aligned}
\frac{1}{\mathrm{n}}\left[\sum_{\mathrm{y}<\mathrm{y}_{\mathrm{p}}} \mathrm{n}^{\mathrm{y}}+\sum_{\mathrm{y}<\mathrm{y}_{\mathrm{c}}(\mathrm{t}, \tilde{\mathrm{G}}(\mathrm{t}))} \mathrm{n}^{\mathrm{y}}\right] \leq .5 \\
\leq \frac{1}{\mathrm{n}}\left[\sum_{\mathrm{y} \leq \mathrm{y}_{\mathrm{p}}} \mathrm{n}^{\mathrm{y}}+\sum_{\mathrm{y}<\mathrm{y}_{\mathrm{c}}(\mathrm{t}, \tilde{\mathrm{G}}(\mathrm{t}))} \mathrm{n}^{\mathrm{y}}\right] .
\end{aligned}
$$

Proof. a. Let $\mathrm{E}$ denote a point on $\tilde{\mathrm{G}}(\mathrm{t})$ that is most preferred by the median-income agent. Figure 4A depicts an example, with $\mathrm{V}^{\mathrm{y}_{\mathrm{p}}}$ a median-income agent's indifference curve through

\footnotetext{
${ }^{8}$ If no type $y_{c}$ exists then the second sum in each bracketed term vanishes.
} 
point E. We show first that point $\mathrm{E}$ is an equilibrium. ${ }^{9}$ As depicted in Figure $4 \mathrm{~B}$, use $\mathrm{V}^{\mathrm{y}_{\mathrm{p}}}$ and point $\mathrm{E}$ to partition the $(\mathrm{t}, \mathrm{G})$ plane into four non-intersecting sets, $\mathrm{A}, \mathrm{B}, \mathrm{C}$, and $\mathrm{D}$, formally defined on the Figure. Point E is majority preferred to every attainable point. Points in D are unattainable by revealed preference. Point $\mathrm{E}$ is Pareto preferred to every point in A. By the single-crossing property of the indifference curves, point $\mathrm{E}$ is (at least weakly) preferred to any points in $\mathrm{C}$ by all those with income equal to or higher than the median; hence, $\mathrm{E}$ is majority preferred. Analogously, point E is majority preferred to any points in B by those with income equal to or less than the median. Having shown a point most preferred by the median-income agent is an equilibrium, we have established existence.

Now use the same partition to show that equilibrium must be a most preferred point of the median-income household. We show that point $\mathrm{E}$ is preferred by a strict majority to every other feasible point that is not another most preferred point of the median-income agent. Set D, again, contains only infeasible points. Point E is strictly preferred unanimously to all points in A except, perhaps, to points in A having the same G as does E. Strict preference of the medianincome household for E over points in B and over points in A with the same G imply strict preference by all those with income lower than the median by single crossing, hence strict majority preference for E. Analogously, points in C would be majority defeated by $\mathrm{E}$ by those with median and higher income.

Note that neither argument requires that $\mathrm{E}$ be an interior point (i.e., $\mathrm{t} \neq 0$ or 1$){ }^{10}$ b. Condition (10) is a necessary condition for equilibrium under SDI, that ensures the equilibrium

\footnotetext{
${ }^{9}$ The "single-crossing" argument we make is not new. See, e.g., Epple and Romer (1991). The idea has roots in Roberts (1977).

${ }^{10}$ Most importantly, equilibrium can have $\mathrm{t}=0$ as we will show. Set $\mathrm{C}$ is then empty.
} 
point cannot be defeated by local alternatives to the (locally) preferred choice of an agent with income $\mathrm{y}_{\mathrm{p}}$. We know from Proposition 1 that an equilibrium point must be a local maximum of $\mathrm{V}(\mathrm{t}, \tilde{\mathrm{G}}(\mathrm{t}))$ over $\mathrm{t}$ for some agent and that agent must be a noncontributor. Hence, take any candidate income type $\mathrm{y}_{\mathrm{p}}$ for whom the point $(\mathrm{t}, \tilde{\mathrm{G}}(\mathrm{t}))$ locally maximizes utility and with the latter restriction. Using the properties of the indifference mapping, observe that:

(P2.I) Any types having $y<y_{p}$ or $y \geq y_{c}(t, \tilde{G}(t))$ have a steeper indifference curve at the point in question.

(P2.ii) Any types with $\mathrm{y} \in\left(\mathrm{y}_{\mathrm{p}}, \mathrm{y}_{\mathrm{c}}\right)$ have flatter indifference curves at the point in question. If condition (9) on $\mathrm{y}_{\mathrm{p}}$ is not satisfied, then either:

(P2.iii) $.5<\frac{1}{\mathrm{n}}\left[\sum_{\mathrm{y}<\mathrm{y}_{\mathrm{p}}} \mathrm{n}^{\mathrm{y}}+\sum_{\mathrm{y}<\mathrm{y}_{\mathrm{c}}} \mathrm{n}^{\mathrm{y}}\right]$ or (P2.iv) $.5>\frac{1}{\mathrm{n}}\left[\sum_{\mathrm{y} \leq \mathrm{y}_{\mathrm{p}}}^{\mathrm{y}<\mathrm{y}_{\mathrm{p}}} \mathrm{n}^{\mathrm{y}}+\sum_{\mathrm{y}<\mathrm{y}_{\mathrm{c}}}^{\mathrm{y}<\mathrm{y}_{\mathrm{c}}} \mathrm{n}^{\mathrm{y}}\right]$.

Suppose (P2.iii). Then a strict majority have steeper indifference curves at the point in question. If agent with income $\mathrm{y}_{\mathrm{p}-1}$ (i.e., the next income lower than $\mathrm{y}_{\mathrm{p}}$ ) has a more preferred point locally, then all incomes in the sums on the right-hand side of (P2.iii) do as well, and we have contradicted the point being an equilibrium. ${ }^{11}$ If not, then agents with income $\mathrm{y}_{\mathrm{p}-1}$ prefer the initial point locally as well (which can happen if we are at a kink or a corner of $\tilde{G}(t)$ ), and redefine the pivotal voter to have income $\mathrm{y}_{\mathrm{p}-1}$. Either the condition in (10) will be satisfied or (P2.iii) will continue to hold. Note that (P2.iv) cannot hold since its right-hand side now equals what was initially the right-hand side of (P2.iii). If (10) is satisfied, then the point is locally majority preferred. If ( $\mathrm{P} 2$.iii) continues to hold then repeat the process, either eventually generating a contradiction or satisfaction of (10).

If, initially, (10) fails and (P2.iv) holds, then a strict majority has flatter indifference

\footnotetext{
${ }^{11}$ If there is no $\mathrm{y}_{\mathrm{p}-1}$ income, then substitute $\mathrm{y}_{\mathrm{c}}$ for $\mathrm{y}_{\mathrm{p}-1}$ in the argument.
} 
curves than the candidate pivotal voter, and an analogous procedure either generates satisfaction of (10) for some $\mathrm{y}_{\mathrm{i}}$ or a contradiction.

Remarks:

1. Under SRI, the single-crossing property of the indifference mappings guarantees existence of equilibrium. The only requirement on $\tilde{\mathrm{G}}(\mathrm{t})$ is that it is a well defined function so voters can optimize. The indirect utility function $V(t, \tilde{G}(t))$ need not be single peaked in $t$ for example. In fact, $\tilde{G}(t)$ will frequently be convex, as for CES utility function, with then multiple peaks of $\mathrm{V}$ not unusual. Single crossing with SRI implies that if a median-income agent prefers a point on $\tilde{\mathrm{G}}(\mathrm{t})$ with higher $\mathrm{t}$ and $\mathrm{G}$ to another point, then all those with higher income share this preference. If a median-income agent prefers a point with lower $t$ and $\mathrm{G}$ to another point on $\tilde{\mathrm{G}}(\mathrm{t})$, then all those will lower income will share that preference. Hence, the preferred point of a median-income agent is majority preferred. Variations in the model that preserve single crossing will preserve existence. Agents might differ in income and, independently, preferences for $\mathrm{G}$ as captured by a taste parameter, $\theta: \mathrm{U}=\mathrm{U}(\mathrm{x} \theta, \mathrm{G}) .{ }^{12}$ With the same assumptions under SRI on $\mathrm{U}$ for $\theta=1$, single crossing is preserved when agents also differ by $\theta$, existence holds, and so on. ${ }^{13}$

2. Whether or not single crossing is satisfied, if equilibrium exists, then the preference mapping at the equilibrium point identifies the pivotal voter. Any agents who make a voluntary contribution favor local tax increases as we have discussed. The latter agents are the richest segment of the population. The marginal willingness to bear a higher tax for increased G rises

where $\mathrm{n}^{\mathrm{y} \theta}$ is the number of agents with values $\mathrm{y}$ and $\theta$.

\footnotetext{
${ }^{12}$ Other parameterizations also preserve single crossing, but this may be the simplest to work with.

${ }^{13}$ A pivotal voter has $\mathrm{y}^{\mathrm{p}}$ and $\theta^{\mathrm{p}}$ such that: $\frac{1}{\mathrm{n}}\left[\sum_{\mathrm{y}<\mathrm{y}} \sum_{\theta \leq \theta^{\mathrm{p}}} \mathrm{n}^{\mathrm{y} \theta}+\sum_{\theta<\theta^{\mathrm{p}}} \mathrm{n}^{\mathrm{y}^{\mathrm{p} \theta}}\right]<.5<\frac{1}{\mathrm{n}_{\mathrm{y} \leq \mathrm{y}^{\mathrm{p}}}} \sum_{\theta \leq \theta^{\mathrm{p}}} \mathrm{n}^{\mathrm{y} \theta}$,
} 
with income among non-contributors given SRI. In the case of SRI then, the preference for a higher marginal tax to increase $\mathrm{G}$ rises with income, and the median-income agent is pivotal. Under SDI, and given an equilibrium point, the marginal willingness to bear a local tax increase for higher $\mathrm{G}$ declines with income among noncontributors. Any contributors are, again, the richest agents and favor local tax increases. If there are any contributors in equilibrium, then the pivotal voter has income below the median, with a coalition of rich and poor favoring higher $\mathrm{t}$ and $\mathrm{G}$, balanced by middle-income types who favor lower $\mathrm{t}$ and G. ${ }^{14}$ Such "ends against the middle equilibria" arise as well in Epple and Romano (1996a,1996b) and Anderberg (1999).

3. Multiplicity of equilibria is possible, but would be a curiosity. Under SRI, if the medianincome agent has multiple most preferred points, then any are equilibria. If we relax our assumption above and let there be two median incomes, then any of either's preferred points are equilibria, and there can be equilibrium points "between." Similar possibilities arise under SDI. The main point, however, is that any of these possibilities only arise with measure zero under parameterizations, and so do not warrant much attention in our opinion.

We now ask whether the collective prefers dual provision over either pure public or pure voluntary provision. Specifically, we assume simultaneous voting over the regime choice and income tax rate, followed by voluntary provision if allowed. The regimes are public only (PO), voluntary only (VO), or dual public-voluntary (PV), with the income tax required to be zero in the case of VO. We assume further that there exists an equilibrium tax given PO or PV. Either single crossing assumption is enough for existence under $\mathrm{PO}$, but single crossing is unnecessary

\footnotetext{
${ }^{14}$ Because the equilibrium can be at a corner or kink of $\tilde{G}(t)$ (see the appendix), multiple income types may prefer no local deviations from the equilibrium point. The statement in the text is then not precise.
} 
(Epple and Romer, 1991). SRI is then a sufficient condition for existence in both regimes, but is not necessary!

Proposition 3. Allowing dual provision is always an equilibrium, and doing so is the only equilibrium if dual provision necessarily arises under PV.

Proof. Let $\mathrm{t}_{\mathrm{R}}$ denote the majority choice of tax rate under regime $\mathrm{R} \in\{\mathrm{PO}, \mathrm{VO}, \mathrm{PV}\}$, with $\mathrm{t}_{\mathrm{VO}} \equiv 0$. For any given $t$, voluntary contributions benefit everyone, implying $(\mathrm{t}, \mathrm{PV})$ is Pareto preferred to $(t, P O)$. By definition of $t_{\mathrm{PV}},\left(t_{\mathrm{PV}}, \mathrm{PV}\right)$ is majority preferred to any $(\mathrm{t}, \mathrm{PV})$, implying $\left(\mathrm{t}_{\mathrm{PV}}, \mathrm{PV}\right)$ is majority preferred to any $(\mathrm{t}, \mathrm{PO})$. The majority preference for $\left(\mathrm{t}_{\mathrm{PV}}, \mathrm{PV}\right)$ is strict if and only if voluntary provision actually arises under PV. Otherwise, the two regimes have the same outcome and tie in voting. Since $\left(\mathrm{t}_{\mathrm{VO}}, \mathrm{VO}\right)$ is equivalent to $(0, \mathrm{PV}),\left(\mathrm{t}_{\mathrm{PV}}, \mathrm{PV}\right)$ is majority preferred to $\left(\mathrm{t}_{\mathrm{vO}}, \mathrm{VO}\right)$, and strictly if and only if there is actually public provision under PV. Absent the latter, VO and PV are equivalent and tie. Combining these results, the Proposition follows.

\section{Remarks:}

1. Given voluntary provision is allowed, the majority preference for allowing public provision is trivial given that the majority can choose zero tax. Given public provision is permitted, it is less obvious that allowing voluntary provision will be the collective choice. While allowing voluntary provision is Pareto improving for given tax, the equilibrium tax choice changes with the regime. This is because the production possibilities change, and the pivotal voter may change as well (e.g., under SDI). Later we will see how some types can lose with a switch from PO to PV.

2. If, instead of simultaneous voting over tax and regime, voting is sequential, then the results go 
through for either order of elections. If the regime is first selected, followed by the tax (except under $\mathrm{VO})$, then the voting is effectively over the three alternatives $\left(t_{\mathrm{R}}, \mathrm{R}\right), \mathrm{R} \in\{\mathrm{PO}, \mathrm{VO}, \mathrm{PV}\}$. From the Proof of Proposition 3, it is easy to see that $\left(\mathrm{t}_{\mathrm{PV}}, \mathrm{PV}\right)$ is (at least weakly) majority preferred. If the tax is first selected followed by regime, with selection of VO in the second stage voiding the tax, again the Proof can be easily modified to show $\left(\mathrm{t}_{\mathrm{PV}}, \mathrm{PV}\right)$ is the outcome.

Does allowing dual provision increase the supply of the public good? An issue is whether dual provision actually arises given it is permitted. This depends on parameters and is examined in the next section. Assuming dual provision materializes, ordinary demand, $g^{d}(p, y)$, now with price explicit, is useful for analyzing trade offs. Let $\mathrm{y}_{\text {med }}$ denote median income and $\mathrm{G}_{\mathrm{R}}$ equilibrium provision of $\mathrm{G}$ under regime $\mathrm{R}$. We have:

Proposition 4. Given positive public provision and voluntary contributions under PV:

a. $\mathrm{G}_{\mathrm{PV}}>\mathrm{G}_{\mathrm{VO}}$.

b. Either $G_{P V}$ greater than or less than $G_{P O}$ is possible. $G_{P O}$ is given by $g\left(\frac{d}{n-\frac{y_{m e d}}{n}}, y_{\text {med }}\right)$ and $G_{P V}$ is given by $g\left(\frac{\mathrm{d}_{\mathrm{p}}}{\tilde{\mathrm{G}}^{\prime}}, \mathrm{y}_{\mathrm{p}}\left(1-\mathrm{t}+\frac{\tilde{\mathrm{G}}}{\tilde{\mathrm{G}}^{\prime}}\right)\right)$ when equilibrium under PV is at a tangency. Under SRI, in going from $\mathrm{PO}$ to $\mathrm{PV}$, there is a positive income effect on provision of $\mathrm{G}$, but a negative price effect.

Proof. a. Obviously this holds if $\tilde{G}$ is everywhere upward sloping. We showed in the Proof of Proposition 1 that equilibrium cannot arise with $t \in\left(0, t^{* *}\right]$ in a case with vertical segment of $\tilde{\mathrm{G}}$ (see Figure 3A), thus establishing the result.

b. Whether SRI or SDI holds, equilibrium under PO is at a median-income agent's most preferred point on $\mathrm{G}=\mathrm{nty}$, hence satisfies: 


$$
\frac{U_{G}\left(y_{\text {med }}(1-t), n t \bar{y}\right)}{U_{x}(\cdot)}=\frac{y_{\text {med }}}{n \bar{y}}
$$

Rewriting the arguments on the left-hand side of (11) implies $\mathrm{G}_{\mathrm{PO}}=\mathrm{g}\left(\frac{\mathrm{d}}{\mathrm{n} \overline{\mathrm{med}}}, \mathrm{y}_{\text {med }}\right)$. Given equilibrium is at a tangency under PV, using Proposition 1 and (L2.iii), it satisfies:

$\frac{\mathrm{U}_{\mathrm{G}}\left(\mathrm{y}_{\mathrm{p}}(1-\mathrm{t}), \tilde{\mathrm{G}}\right)}{\mathrm{U}_{\mathrm{x}}}=\frac{\mathrm{y}_{\mathrm{p}}}{\tilde{\mathrm{G}}^{\prime}}$. Analogous interpretation of the latter implies $\mathrm{G}_{\mathrm{PV}}$ is as stated in the Proposition. Under SRI, $y_{p}=y_{\text {med }}$ (Proposition 2a). One can see by inspection of (9) that, given dual provision under PV, $\tilde{\mathrm{G}}^{\prime}<\mathrm{ny}$, implying the stated negative price effect. Using (8) and (9), $\tilde{\mathrm{G}}>\mathrm{t} \tilde{\mathrm{G}}^{\prime}$, implying the positive income effect. Hence, either $\mathrm{G}_{\mathrm{PV}}$ less than or greater than $\mathrm{G}_{\mathrm{PO}}$ is feasible, as is confirmed computationally in the next section.

Remarks:

1. The restriction in Proposition 4 to the case of a tangency under PV permits the use of ordinary demand to clarify the countervailing price and income effects of going between PO and PV. We will see in the next section that there is nothing atypical about a tangency solution. Graphically, the income and price effects correspond respectively to the outward shift but steepening of the budget constraint in the $(\mathrm{G}, \mathrm{t})$ plane. The "price increase" under PV is due to the crowding out of voluntary provision that results as $\mathrm{t}$ is increased.

2. Under SDI, the income of the pivotal voter would decline in moving from PO to PV. This tempers or reverses the income effect, but does the same to the price effect. Hence, the net effect on provision of $\mathrm{G}$ is ambiguous.

\section{Large Economies and Computational Analysis}

Here we show that, given a PV regime, dual provision will not actually materialize in a 
sufficiently large economy. After demonstrating this theoretically, we present some computational analysis to provide perspective on how large the economy must be to preclude dual provision. As well, the computational analysis illustrates earlier results for smaller economies.

Theoretical Analysis. To let the economy grow, replicate it by a positive integer factor $\mathrm{S}$. That is, let the numbers of income-types be given by: $\left(\mathrm{Sn}^{\mathrm{y}_{1}}, \mathrm{Sn}^{\mathrm{y}_{2}}, \ldots, \mathrm{Sn}^{\mathrm{y}_{\mathrm{Y}}}\right)$.

Proposition 5. For S sufficiently high, only public provision will arise in equilibrium of the PV regime.

Proof. We show that there is a finite upper bound on $\mathrm{G}$ for any $\mathrm{S}$ above which no one would contribute. Then we show that for all $\mathrm{S}$ exceeding some $\mathrm{S}_{\mathrm{o}}$, the pivotal voter's choice of $\mathrm{t}$ will lead to higher $\mathrm{G}$, hence no voluntary contributions.

The upper bound $\mathrm{G}^{*}$ satisfies $\mathrm{g}^{\mathrm{d}}\left(\mathrm{y}_{\mathrm{Y}}+\mathrm{G}^{*}\right)=\mathrm{G}^{*}$. Using (1), a finite and unique $\mathrm{G}^{*}$ exists. By Lemma 1, $\mathrm{G}^{*}$ is the G-axis intercept of the $\tilde{\mathfrak{t}}$ locus for the highest income type. Again by Lemma 1 , if $\mathrm{G}>\mathrm{G}^{*}$ in equilibrium, then no type makes a voluntary contribution. ${ }^{15}$

Select an arbitrary $t_{o}$ bounded above (below) 0 (1). Let $s_{\mathrm{o}}$ satisfy: $\mathrm{U}\left(\mathrm{y}_{\mathrm{p}}\left(1-\mathrm{t}_{\mathrm{o}}\right), \mathrm{s}_{\mathrm{o}} \mathrm{nt}_{\mathrm{o}} \overline{\mathrm{y}}\right)=\mathrm{U}\left(\mathrm{y}_{\mathrm{p}}, \mathrm{G} *\right)$, noting that $\mathrm{s}_{\mathrm{o}}$ need not be an integer. Let $\mathrm{S}_{\mathrm{o}}\left(\mathrm{t}_{\mathrm{o}}\right)$ denote the minimum integer $S_{o} \geq S_{o}$. Obviously, for all $S \geq S_{o}, \operatorname{Max}_{t} U\left(y_{p}(1-t), S n t \bar{y}\right)$ has $\mathrm{U} \geq \mathrm{U}\left(\mathrm{y}_{\mathrm{p}}, \mathrm{G} *\right)$. The latter inequality and that the first argument of the pivotal voter's maximized utility cannot exeed $\mathrm{y}_{\mathrm{p}}$ implies $\mathrm{G} \geq \mathrm{G} *$. Hence, the pivotal voter's optimum and

\footnotetext{
${ }^{15}$ Another interpretation of $\mathrm{G}^{*}$ is that it is an upper bound on $\mathrm{G}$ for any size economy with no public provision. This has been shown by Fries, et. al. (1991) in a model like the present with a finite number of types and by Andreoni (1988) in a model with a continuum of types.
} 
equilibrium has no voluntary contributions.

The proof formalizes the intuitive argument that there is an upper bound on voluntary contributions while, in a large enough economy, a positive tax rate allows enough more public provision that the pivotal voter has higher utility.

As is realistic at least for some goods, now suppose some types exist who are indifferent to consumption of the good. So their preference is for zero tax. If they are in a majority (public theater?), then only voluntary provision characterizes equilibrium. If they are not in a majority, then Proposition 5 still holds. We have then:

Corollary to Proposition 5. Either just public provision or just voluntary provision arises in equilibrium in a large economy if there can exist types who are indifferent to the public good.

Our purpose for stating this obvious result is because we think it may be relevant empirically. The relevance of nonexcludability and noncongestion to the large-economy results is examined in Section 5.

Computational Analysis. We now turn to a computational example to illustrate properties of equilibrium. For our computational example we choose the CES utility function above:

$\mathrm{U}=\left[\mathrm{ax}^{\alpha}+(1-\mathrm{a}) \mathrm{G}^{\alpha}\right]^{\frac{1}{\alpha}}$. This utility function implies demand function:

$$
g^{d}(y)=A Y \text { where } A \equiv \frac{(1-a)^{\frac{1}{1-\alpha}}}{a^{\frac{1}{1-\alpha}}+(1-a)^{\frac{1}{1-\alpha}}}
$$

Preferences satisfying SRI are empirically relevant and existence holds generally, so we focus on preferences satisfying this condition. SRI holds when $\alpha<0$. The elasticity of substitutition, $\sigma$, 
is equal to $1 /(1-\alpha)$. Thus, SRI implies the elasticity of substitution lies in the interval $(0,1)$.

We consider examples with three income types and choose numbers of the three types such that the middle-income type is the pivotal voter. We parametrically vary $\sigma$ (equivalently, $\alpha$ ), incomes, and numbers of the three types to illustrate various properties of equilibria. When varying $\sigma$, we adjust the parameter a in the utility function so that $\mathrm{A}=.2$ (with one exception that is noted). This avoids confounding the effects of varying $\sigma$ with the effects of rotating the Engel curve. Thus, regardless of the value of $\sigma$, an individual purchasing $\mathrm{G}$ in a private market would spend $20 \%$ of her income on $\mathrm{G}$.

As a baseline, we consider a small economy with $\mathrm{y}_{1}=\$ 8,000, \mathrm{y}_{2}=\$ 25,000, \mathrm{y}_{3}=\$ 55,000$, $\mathrm{n}^{1}=10, \mathrm{n}^{2}=10$, and $\mathrm{n}^{3}=1$. Figure $5 \mathrm{~A}$ displays the equilibrium $\mathrm{G}$ as $\sigma($ or $\alpha)$ varies for this baseline case, with and without voluntary contributions allowed, the former the political equilibrium. For values of $\sigma$ from $2 / 9$ up to approximately $2 / 5$, positive voluntary contributions arise in political equilibrium. Up to this value of $\sigma$, equilibria are depicted as the dashed curve; the allocations without voluntary contributions allowed are not equilibria. Beyond the value of $\sigma$ $\approx 2 / 5$, voluntary contributions are crowded out by public provision, and equilibria are as depicted by the solid curve. The equilibrium allocation jumps discretely at this point as the pivotal voter's preference for the public good becomes sufficiently strong that there is a discrete increase in the tax rate, a discrete increase in $\mathrm{G}$, and a cessation of voluntary contributions. The panels of Figure 6 depict voting equilibria at such points of discontinuity in provision of the public good. Figure 6A corresponds to the example in Figure 5A, where equilibrium jumps from a corner at $\mathrm{E}_{1}$ with positive voluntary giving, to $\mathrm{E}_{2}$ with zero voluntary giving as $\sigma$ crosses the threshold. Now setting $\mathrm{y}_{2}=\$ 36,000$ and fixing A equal to .5 , Figure $5 \mathrm{~B}$ depicts equilibrium $\mathrm{G}$ as $\sigma$ varies over a low range, again compared to the case without voluntary contributions permitted. Each of the 
voluntary contribution equilibria in Figure 5B are at a tangency like at $\mathrm{E}_{1}$ in Figure 6B. Increasing $\sigma$ further would lead to a jump to a point like $\mathrm{E}_{2}$ in Figure $6 \mathrm{~B}$ (not shown in Figure 5B). We see from the panels of Figure 5 that public provision without voluntary contributions can be either above or below the level achieved when voluntary contributions are permitted, completing the Proof of Proposition 4. Note that the richest type can be worse off with voluntary contributions permitted. In Figure 5A when public good provision is the same with and without voluntary contributions, the richest type supplies all the public good in the former case and is thus worse off.

Beginning again with baseline values and $\sigma=2 / 9$, Figure 7 illustrates the effect of increasing the number of high-income types. The allocations without voluntary contributions are not political equilibria over the range shown, but are included for comparison. We have also plotted such figures for alternative values of $\sigma$. For smaller values of $\sigma$, the PV curve shifts up relative to the PO curve whereas with larger values of $\sigma$, the $\mathrm{PV}$ curve shifts down relative to the PO curve.

We next illustrate the effect of increasing the population via a proportionate increase in the numbers of all types. Figure 8 shows equilibrium provision beginning with baseline values and $\sigma=1 / 6$ for population sizes up to 50 times the initial numbers. The allocations without voluntary contributions are not equilibria over the range shown. Increasing the benchmark population by a multiple of 100 (not shown) results in public provision that is sufficiently high to crowd out private contributions. We have purposely chosen a case where the population must be moderately large for this crowding out. Recall from Figure 5 A that once $\sigma$ exceeds $2 / 5$ voluntary contributions cease for an economy with population of only 21 !

Our last computational exercise focuses on the effects of varying the income of the 
pivotal voter. Returning to the baseline values, we vary $\mathrm{y}_{2}$ between $\$ 8,000\left(\mathrm{y}_{1}\right)$ and $\$ 55,000\left(\mathrm{y}_{3}\right)$ and show the effects on the equilibrium tax rate for several values of $\sigma$ in Figure 9. We observe the jumps in equilibria as $\mathrm{y}_{2}$ rises, again when voluntary contributions cease. For $\sigma=1 / 3$, equilibrium is of the corner type whenever voluntary contributions materialize. For the lower values of $\sigma$ shown, as $y_{2}$ rises, equilibrium initially has only voluntary contributions $(t=0)$, then dual provision ( $\mathrm{t}>0$ before the jump), and then only public provision. For our utility function, the ranges where we have found actual dual provision tend to be relatively narrow when they exist at all.

\section{Interpretations}

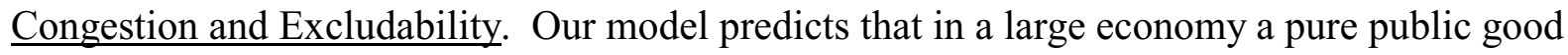
will be exclusively publicly provided, unless a majority find it of sufficiently little value. Yet significant dual provision of some goods does arise, including education and health care, where there is universal access to public provision in many economies. That is, public provision is not just for the poor. While we are persuaded that warm-glow effects are significant determinants of voluntary contributions in many cases (Andreoni $(1989,1990)$ ), it is hard to believe that support of some goods would generate a warm glow. ${ }^{16}$ Do people get a warm glow when they contribute to their political party?

Here we examine the role of "publicness" of the good, while maintaining purely selfish motives of potential contributors. The pure public good above is neither congested nor excludable. We examine the significance of these attributes in impeding joint provision in large economies.

\footnotetext{
${ }^{16}$ See Romano and Yildirim (forthcoming) and the references therein for analysis of alternative motives of contributors.
} 
Table 1 summarizes our approach and findings, and contains a few examples. We consider the large-economy results in four stark cases of the good. By "congested" we mean individual consumption equals $\mathrm{G} / \mathrm{n}$, where $\mathrm{G}$ is total (nonexcluded) expenditure. By "excludable" we mean any provider of the good can costlessly prevent consumption of any agent. This may permit for-profit provision, with circumstances clarified below. In any case, we assume public provision is universally provided and any private provision available to an individual supplements public consumption. ${ }^{17}$ Whether a good is congested and/or excludable is, realistically, a matter of degree and sometimes endogenous, as shaped by technical and institutional factors. In Table 1, we categorize a clean public beach as congested and nonexcludable, having in mind crowded beaches with rigid open access laws. We categorize an art collection as noncongested having in mind the rarity of congestion in most art galleries. And so on.

While the analysis above shows dual provision of a pure public good is highly unlikely in a large economy, Epple and Romano (1996a) showed that dual provision of a congested and excludable good, i.e., a private good, is predicted in a large economy for realistic parameterization. This was shown in the analogous model to that here, where individual consumption equals ty plus any competitively supplied supplement the individual chooses to purchase. $^{18}$

Consider next a congested but nonexcludable good. Each agent's consumption equals

\footnotetext{
${ }^{17}$ Epple and Romano (1996b) and Glomm and Ravikumar (1998) examine dual provision of a congested and excludable good when consumers must choose between public and private provision. This is to be contrasted with Epple and Romano (1996a) which is discussed below.

${ }^{18}$ The crucial requirement is that the median income is below the mean. The incentive of the pivotal voter to support public provision is to effect redistribution. See Meltzer and Richards (1985), Besley and Coate (1991), Fernandez and Rogerson (1998), Anderberg (1999), and Casamatta, Cremer and Pestieau (2000) for related analyses. Also, see the previous footnote.
} 
$\mathrm{G} / \mathrm{n}$, where $\mathrm{G}$ is total economy expenditure on the good. Dual provision will fail to arise in a large economy (except in extraordinary circumstances). If a majority fails to value the good, obviously only voluntary contributions will arise. Suppose, then, that everyone values the good. One can closely follow the development of the theoretical results in Sections 2 - 4 and verify that Propositions 1, 2, and 3 continue to hold among the other results. The preference mapping in the $(\mathrm{G}, \mathrm{t})$ plane, as well as the supply function $\tilde{\mathrm{G}}(\mathrm{t})$, are qualitatively indistinguishable from the noncongested case. More to the point, the constructs are quantitatively similar (except for cardinal utility values), and one finds again that with (not so) large n only public provision results.

The quantitative similarity is, perhaps, surprising. A simple example conveys the intuition. Suppose that preferences over the two goods are Cobb-Douglas:

$$
\mathrm{U}=\mathrm{x}^{\beta} \mathrm{Z}^{1-\beta}
$$

where $\mathrm{Z}=\mathrm{G}$ in the noncongested case and $\mathrm{Z}=\mathrm{G} / \mathrm{n}$ in the congested case. ${ }^{19}$ Since utility functions $\mathrm{n}^{\beta-1} \mathrm{x}^{\beta} \mathrm{G}^{\beta}$ and $\mathrm{x}^{\beta} \mathrm{G}^{\beta}$ are ordinally equivalent, the equilibrium values are precisely the same in the two cases, except that utility values are lower in the congested case. In this case, then, if and only if $\mathrm{n}$ is such that only public provision will arise when the good is noncongested, will the same occur in the congested case. ${ }^{20}$

The intuition is that in going to the congested case there is a negative substitution or price effect on the provision of $\mathrm{G}$, but a positive income effect. Using the notation in (13), to produce

\footnotetext{
${ }^{19}$ The Cobb-Douglas utility function has both unitary income and price demand elasticities, hence is the boundary case between SRI and SDI. Preferences mappings in the (G,t) plane of noncontributors in both cases are independent of income, i.e., noncontributors agree (locally) on the preferred $(\mathrm{G}, \mathrm{t})$.

${ }^{20}$ The argument applies to more general forms of congestion. Redefine $Z \equiv G / h(n)$ with h'>0, and the logic is seen easily to go through.
} 
the same level of $\mathrm{Z}$ in the congested case as the noncongested case costs the economy $\mathrm{n}$ times more; the negative price effect. However, for given expenditure on the good, the ratio of the economy's income to the good $\mathrm{Z}$ is $\mathrm{n}$ times higher; the positive income effect. These offset exactly in the Cobb-Douglas case. While departing from this case will lead to outcomes in the two cases that vary somewhat, quantitative differences will be limited by the two (somewhat) offsetting effects. ${ }^{21}$

The remaining of the four cases in Table 1 is that of an excludable but noncongested good. To analyze this case, we need to characterize market provision of an excludable and noncongested supplemental good. We presume that the market functions as efficiently as is technically feasible. More specifically, we assume that for given t:

$$
\mathrm{G}_{\mathrm{m}}=0 \text { if } \sum_{\mathrm{y}} \mathrm{n} \frac{\mathrm{U}_{\mathrm{G}}(\mathrm{y}(1-\mathrm{t}), \mathrm{nty})}{\mathrm{U}_{\mathrm{x}}(\cdot)} \leq 1
$$

and $\mathrm{G}_{\mathrm{m}}$ otherwise satisfies:

$$
\sum_{y} n \frac{U_{G}\left(y(1-t)-p^{y} G_{m}, n t \bar{y}+G_{m}\right)}{U_{x}(\cdot)}=1
$$

where

$$
\mathrm{p}^{\mathrm{y}}=\frac{\mathrm{U}_{\mathrm{G}}(\cdot)}{\mathrm{U}_{\mathrm{x}}(\cdot)} \text { for all } \mathrm{y}
$$

\footnotetext{
${ }^{21}$ A piece of the general analysis of the congested case may help to clarify intuition further. Recall that in the noncongested case the locus of points in the $(\mathrm{G}, \mathrm{t})$ plane such that an agent just makes zero voluntary contribution satisfies: $1 \cdot \mathrm{g}(1, \mathrm{y}(1-\mathrm{t})+\mathrm{G})=\mathrm{G}$, where $\mathrm{g}^{\mathrm{d}}(\cdot)$ is ordinary demand written as a function of price and income respectively. In the congested case, that locus satisfies: $n g(n, y(1-t)+G)=G$. The latter illustrates again the trade off in going to the congested case.
} 
and $\mathrm{G}_{\mathrm{m}}$ denotes market provision by some seller. If (14) is satisfied it is impossible for a seller of $\mathrm{G}$ to be profitable. Otherwise, the solution to (15.1) and (15.2) is the unique value of $\mathrm{G}_{\mathrm{m}}$ that precludes entry assuming type-dependent linear pricing. Hence, we are assuming sellers can price discriminate. While one can forcefully debate whether the market process is likely to produce such an equilibrium, we firmly believe this specification is the appropriate choice for the present analysis. Alternative specifications amount to incorporating some market inefficiency, from which we want to abstract, to isolate the effects of interest and to be most consistent with the rest of the analysis (e.g., our (1996a) analysis of private goods).

One can proceed here generally as above, but the simple Cobb-Douglas case suffices to make our main point that dual provision may well arise in a large economy. Letting $\tilde{\mathrm{t}}$ denote the threshold tax below (above) which $\mathrm{G}_{\mathrm{m}}>(=)$, using (13) - (15.2), one obtains:

$$
\begin{aligned}
& \tilde{\mathrm{t}}=1-\beta ; \\
& U(t, y)=\begin{array}{ll}
{\left[(1-t) y-p^{y}(t) G_{m}(t)\right]^{\beta}\left(n t \bar{y}+G_{m}(t)\right)^{1-\beta}} & \text { if } t \leq \tilde{t} \\
{[(1-t) y]^{\beta}(n t \bar{y})^{1-\beta}} & \text { if } t \geq \tilde{t},
\end{array} \\
& \mathrm{G}_{m}(\mathrm{t})=n \overline{\mathrm{y}}(\tilde{\mathrm{t}}-\mathrm{t}) \text { for } \mathrm{t} \leq \tilde{\mathrm{t}}
\end{aligned}
$$

and

$$
\mathrm{p}^{\mathrm{y}}(\mathrm{t})=\frac{(1-\beta) \mathrm{y}}{\tilde{\mathrm{t} n \bar{y}}} \text { for } \mathrm{t} \leq \tilde{\mathrm{t}}
$$

Substituting from (18) and (19) into the upper line of (17) and using (16), yields:

$$
\mathrm{U}(\mathrm{t}, \mathrm{y})=\beta^{\beta} \mathrm{y}^{\beta}[\mathrm{ny}(1-\beta)]^{1-\beta} \text { for } \mathrm{t} \leq 1-\beta \text {. }
$$


Differentiating (20) and the lower line of (17), one obtains:

$$
\frac{\partial \mathrm{U}}{\partial \mathrm{t}}=(<) 0 \text { as } \mathrm{t}<(>) 1-\beta \text { for all } \mathrm{y} \text {. }
$$

Not only is there unanimity of preferences, but any $t \in[0,1-\beta]$ is an equilibrium.

The implication is that equilibrium can have dual provision or only market or only public provision. Here, $\mathrm{G}$ is constant across the equilibria, with increased taxation exactly offset by reduced market costs for each agent. While the Cobb-Douglas case is a special one, it is not key to the possibility of dual provision. One can perturb the economy in various ways and obtain dual provision as the unique equilibrium. ${ }^{22}$ Our point is not that we should necessarily expect dual provision when a good is excludable. Rather, our point is that it takes nothing unusual to predict dual provision in a large economy when a good is excludable, whether congested or not, while it would be pathological to obtain dual provision of a nonexcludable good (warm-glow motives aside). Put differently, for a good that is widely demanded, it is nonexcludability that is fundamental to limiting market provision, not congestion properties.

The Political Preference of Contributors. Another theme of the analysis that we would like to stress concerns the political preference of voluntary contributors to nonexcludable goods, congested or not. Their preference is for higher taxes, with a strict preference unless everyone is contributing. Technically, this corresponds in the (G,t) plane to noncontributors' locally vertical indifference curves and an upward sloping aggregate supply curve, the latter unless everyone is contributing. This political force will be present whether or not equilibrium is determined by

\footnotetext{
${ }^{22}$ Suppose for example that provision of $\mathrm{G}$ by the government has average cost that is slightly U-shaped with minimum cost just below market cost at supply level near one-half the equilibrium amount in the text. Then equilibrium will be unique with dual provision. This perturbation is obviously contrived to get the result while keeping things simple. Note well that perturbations will not change the results in the other three cases.
} 
majority voting. Contributors' preference for higher taxes is a corollary of individual neutrality, i.e., to the individual indifference to supporting production of $\mathrm{G}$ through a tax payment or contribution. Since raising taxes will lead noncontributors to increase their total expenditure, the contributor is better off.

\section{Concluding Remarks}

Previous research has characterized the properties of equilibrium with voluntary giving and investigated the effects of government provision on voluntary contributions. We close the loop by endogenizing collective provision and by endogenizing the choice regime. Regarding the latter, we show that a regime permitting both government and private provision is majoritypreferred to a regime that prohibits either. Regarding the former, we show that voting equilibrium exists fairly generally and establish a variety of results that may provide fruitful grist for empirical testing.

We show that dual provision can indeed occur in equilibrium. Interestingly, while dual provision is always majority preferred, dual provision need not lead to greater total provision than a regime with only public provision. Recognizing that increasing government provision tends to discourage private contributions, the pivotal voter may opt for a low level of government provision, foregoing additional consumption of the public good in order to enjoy relatively low taxes. However, as the population in an economy grows, voluntary contributions grow less rapidly, and a point is eventually reached at which the pivotal voter finds the benefits of increased government provision to outweigh the loss from increased taxes. At that point there is generically a sharp jump in the tax rate and total amount of the public good provided and a concomitant sharp drop in private contributions. We find that the pivotal voter does not make voluntary contributions, and we find that contributors always favor an increase in taxes. The 
underlying force is the same in both cases; contributors can offset their increased tax payments by reducing their own contributions while benefitting from the increased tax revenues from noncontributors. Our analysis also shows that excludability rather than congestion is the fundamental force limiting private provision in large economies. Our theoretical and computational analyses illustrate the dependence of dual provision on the parameters of preferences and the distribution of income, thereby also illustrating the potential scope of the approach in providing a foundation for empirical work in different public-good contexts.

Andreoni $(1989,1990)$ has argued convincingly that models of public goods that do not have a motive for contribution beyond the consumption value of the good cannot account for the amount of private giving that is observed in practice. Nothing in our analysis contradicts this conclusion. He shows that a "warm glow' motive can lead to substantially greater private contributions and less crowding out of private contributions when government provision increases. Adding such considerations in analyzing collective and voluntary provision is a natural and important direction for future research. 


\section{Appendix.}

Proof of Lemma 3. a. Applying the implicit function theorem to (5) and $(6), \tilde{\mathrm{g}}^{\mathrm{y}}(\mathrm{t}, \tilde{\mathrm{G}})$ is everywhere continuous and differentiable, except for the latter at the point where $\tilde{\mathrm{g}}^{\mathrm{y}}$ converges to zero. For given $t, y_{c}(G, t)$ is a step function, that takes discrete jumps up as $G$ rises. $y_{c}$ jumps from $\mathrm{y}_{\mathrm{i}}$ to $\mathrm{y}_{\mathrm{i}+1}$ at value $\left(\mathrm{t}, \mathrm{G}_{\mathrm{i}}\right)$ where $\tilde{\mathrm{g}}^{\mathrm{y}_{\mathrm{i}}}\left(\mathrm{t}, \mathrm{G}_{\mathrm{i}}\right)$ just becomes zero, or, equivalently, where $\mathrm{t}=\tilde{\mathrm{t}}\left(\mathrm{G}_{\mathrm{i}}, \mathrm{y}_{\mathrm{i}}\right)$ (see Figures 1 and 3). Using these facts and (L2.iii), it is clear that (8) has a unique fixed point for all $t$, i.e., is a well defined function. Applying the implicit function theorem to (8), we have also that $\tilde{G}$ is continuous and differentiable except, perhaps, at values $G_{i}$ where $y_{c}$ jumps. Continuity holds everywhere, too, since at a jump point of $\mathrm{y}_{\mathrm{c}}$ from $\mathrm{y}_{\mathrm{i}}$ to $\mathrm{y}_{\mathrm{i}+1}, \tilde{\mathrm{g}}^{\mathrm{y}_{\mathrm{i}}}\left(\mathrm{t}, \mathrm{G}_{\mathrm{i}}\right)$ equals zero (i.e., the sum in (8) is continuous).

b. Given that $\tilde{G}(t)$ is increasing and that there is a $t^{*}<1$ such that $y_{c}\left(\tilde{G}\left(t^{*}\right), t^{*}\right)=y_{Y}$, these follow by inspection of (8). Given that $\tilde{\mathrm{G}}(\mathrm{t})$ is increasing, such a $\mathrm{t}^{*}$ exists since $\tilde{\mathrm{g}}^{\mathrm{y}_{\mathrm{Y}}}(\mathrm{t}, \tilde{\mathrm{G}}(\mathrm{t}))$ is decreasing in $\mathrm{t}$ (see (L2.iii)) and, obviously, equals zero for some $\mathrm{t}^{*}<1$. We show below that $\tilde{G}(t)$ is increasing independent of the results here.

c. In the proof of part a we established differentiability except where $y_{c}$ jumps (as well as when $\mathrm{y}_{\mathrm{c}}$ jumps). Using (L2.iii) and differentiating (8), (9) is calculated.

d. Using (1), inspection of (9) reveals $\tilde{\mathrm{G}}^{\prime{ }^{(+)}}>(=) 0$ for $\mathrm{y}_{\mathrm{c}}>(=) \mathrm{y}_{1}$. If at $\mathrm{t}=0$ all types contribute, then $\tilde{\mathrm{G}}^{/(+)}=0$ on $\left[0, \mathrm{t}^{* *}\right]$ for some $\mathrm{t}^{* *}$ no greater than $\mathrm{t}^{*}$, where $\mathrm{t}^{* *}$ satisfies $\mathrm{y}_{\mathrm{c}}\left(\tilde{\mathrm{G}}\left(\mathrm{t}^{* *}\right), \mathrm{t}^{* *}\right)=\mathrm{y}_{1} \cdot{ }^{23}$

e. This can be seen by inspection of (9), noting that a negative term drops out of the numerator and a positive term drops out of the denominator as kinks are crossed.

f. In this case $\mathrm{g}^{\mathrm{d}}$ is a constant, and, again, the result follows by inspection of (9).

\footnotetext{
${ }^{23}$ Actually, $\mathrm{t}^{* *}=\mathrm{t}^{*}$ if and only if there is just one type. Since we have assumed no type constitutes a majority, it must be that $\mathrm{t}^{* *}<\mathrm{t}^{*}$.
} 
Kinky Equilibria. Two types of equilibria without a tangency of the pivotal voter's indifference curve to $\tilde{\mathrm{G}}(\mathrm{t})$ are possible. One is simply a corner solution at $\mathrm{t}=0$, as depicted in Figure 6A. A corner solution at $\mathrm{t}=1$ is infeasible under our assumptions on $\mathrm{U}$. The other possibility is depicted in Figure A.1. Since:

(a) a noncontributor is pivotal (Proposition 1);

(b) indifference curves are concave in the $(\mathrm{G}, \mathrm{t})$ plane given $\mathrm{g}>0$ (convexity assumptions on $\mathrm{U}$ );

(C) $\tilde{\mathrm{G}}$ flattens as kinks are crossed in the $(\mathrm{G}, \mathrm{t})$ plane (Part e of Lemma 3); and

(d) kinks in $\tilde{G}$ correspond to points where a type just ceases to contribute (Part c of Lemma 3); an equilibrium at a nontangency with $t \in(0,1)$ must be at a kink of both the indifference curve of the pivotal voter and of $\tilde{G}$. It is not possible to have either a nontangency strictly above the kink on the pivotal voter's indifference curve (due to $a, b$, and $c$ above) or to have a kink in just the pivotal voter's indifference curve (due to $d$ above). Note that it is a relatively simple matter computationally to check for either kinky equilibrium possibility.

One-Type Equilibrium. While we have assumed no income-type is in a majority implying multiple types, one can quickly see that a kinky equilibrium does not arise if there is just one type. Equilibrium is at point $\mathrm{E}$ in Figure A.2. In this case, $\tilde{\mathrm{G}}(\mathrm{t})$ has just one kink at the point where voluntary contributions cease, which is then also at the kink of the type's indifference curve through that point (F in Figure A.2). Using (4) and (L2.ii), the right-side derivative of the indifference curve is $1 / y$, while, using (9), the right-side derivative of the public good budget constraint is $1 / n y$. Hence, assuming $n>1$, equilibrium while be higher up on $\tilde{\mathrm{G}}(\mathrm{t})$ at a tangency as depicted. The economic explanation is that point $\mathrm{F}$ is equivalent to the $\mathrm{VO}$ outcome, which has inefficiently little provision, while voting equilibrium is efficient with just one type. 


\section{References}

Anderberg, D. "Determining the Mix of Public and Private Provision of Insurance by Majority Rule.” European Journal of Political Economy 15 (September 1999), 417-440.

Andreoni, James. "Privately Provided Public Goods in a Large Economy: The Limits of Altruism." Journal of Public Economics 35 (1988): 57-73.

. "Giving with Impure Altruism: Applications to Charity and Ricardian Equivalence." Journal of Political Economy 97 (1989): 1447-1458.

. "Impure Altruism and Donations to Public Goods: A Theory of Warm-Glow Giving." Economic Journal 100 (1990): 464-477.

Atkinson, Anthony, and Joseph Stiglitz. Lectures in Public Economics. McGraw Hill, 1980, 507509.

Barr, James L., and Davis, Otto A. "An Elementary Political and Economic Theory of Expenditures of State and Local Government.” Southern Economic Journal 33 (October 1966): 149-165.

Bergstrom, Theodore C. "When Does Majority Rule Supply Public Goods Efficiently." Scandinavian Journal of Economics 81 (October 1979): 227-236.

Bergstrom, Theodore C., Blume, Lawrence, and Varian, Hal. "On the Private Provision of Public Goods.” Journal of Public Economics 29 (1986): 25-49.

Bergstrom, Theodore C., and Goodman, Robert P. "Private Demands for Public Goods." American Economic Review 63 (June 1973): 280-296.

Bernheim, B. Douglas "On the Voluntary and Involuntary Provision of Public Goods." American Economic Review 76 (September 1986): 789-793.

Besley, Timothy, and Coate, Stephen. "Public Provision of Private Goods and the Redistribution of Income." American Economic Review 81 (September 1991): 979-984.

Borcherding, Thomas, and Deacon, Robert. "The Demand for the Services of Non-Federal Governments.” American Economic Review 62 (December 1972): 891-901.

Casamatta, Georges, Cremer, Helmuth, and Pestieau, Pierre. "Political Sustainability and the Design of Social Insurance.” Journal of Public Economics 75 (March 2000): 341-364.

Cornes, R. and Sandler, Todd. "Easy Riders, Joint Production, and Public Goods." Economic Journal 94 (1984): 580-598.

Epple, Dennis and Romano, Richard. "Public Provision of Private Goods.” Journal of Political 
Economy 104 (February 1996a): 57-84.

. "Ends Against the Middle: Determining Public Service Provision When There Are Private Alternatives." Journal of Public Economics 62 (1996): 297-325.

Epple, Dennis and Romer, Thomas. "Mobility and Redistribution.” Journal of Political Economy 99 (August 1991): 828-858.

Fries, Timothy, Golding, Edward, and Romano, Richard. "Private Provision of Public Goods and the Failure of the Neutrality Property in Large Finite Economies." International Economic Review 32 (1991): 147-157.

Glomm, Gerhard, and Ravikumar, B. "Opting Out of Publicly Provided Services: A Majority Voting Result.” Social Choice and Welfare 15 (1998): 187-199.

Gouveia, Miguel. "Majority Rule and the Public Provision of Health Care." Public Choice 93 (December 1997): 21-244.

Kenny, Lawrence W. "The Collective Allocation of Commodities in a Democratic Society: A Generalization." Public Choice 33, no. 2 (!978): 117-20.

Meltzer, Allan H., and Richard, Scott F. "A Positive Theory of In-Kind Transfers and the Negative Income Tax.” Public Choice 47, no. 1 (1985): 231-265.

Mueller, Dennis C. Public Choice II. Cambridge: Cambridge University Press, 1989.

Non-Tax Sources of Revenue for Public Libraries. ALA Survey Report. American Library Association, Office for Research, 1988.

Ordeshook, Peter C. Game Theory and Political Economy. Cambridge: Cambridge University Press, 1986.

Roberts, Kevin W. S. "Voting Over Income Tax Schedules.” Journal of Public Economics 8 (December 1977): 329-340.

Romano, Richard, and Yildirim, Huseyin. "Why Charities Announce Donations: A Positive Perspective." Journal of Public Economics, forthcoming.

Rosett, Richard N. "Art Museums in the United States: A Financial Portrait." Chapter 6 in The Economics of Art Museums, edited by Martin Feldstein. Chicago, IL: The University of Chicago Press (for NBER), 1991.

Scharf, Kimberly A. "Why Are Tax Expenditures for Giving Embodied in Fiscal Constitutions?" Journal of Public Economics 75 (March 2000): 395-388. 
Steinberg, Richard. "Voluntary Donations and Public Expenditures in a Federalist System." American Economic Review 77 (1987): 24-36.

Warr, Peter. "The Private Provision of Public Goods is Independent of the Distribution of Income." Economic Letters 13 (1983): 207-211. 


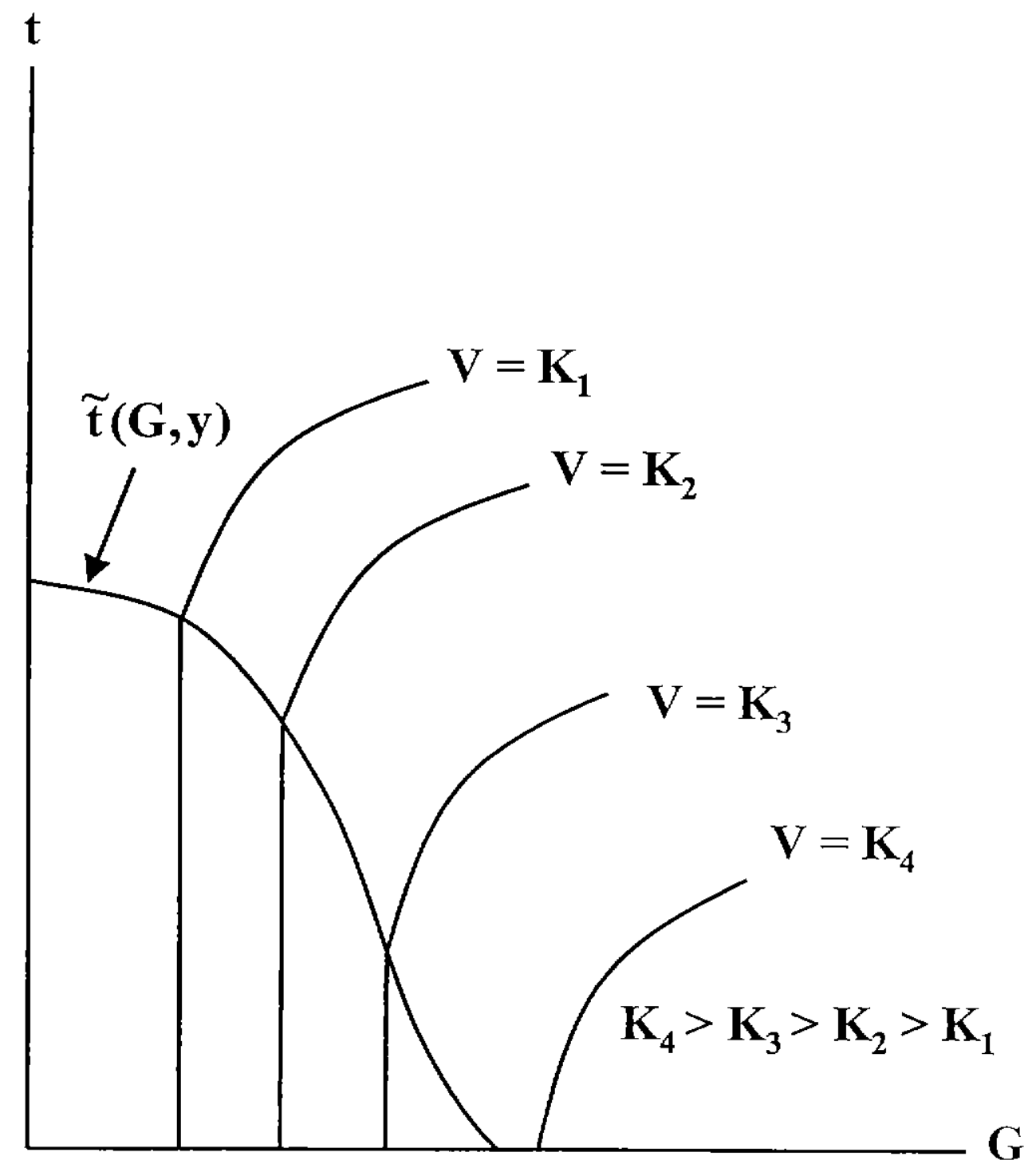

Figure 1: An Agent's Preference Mapping 


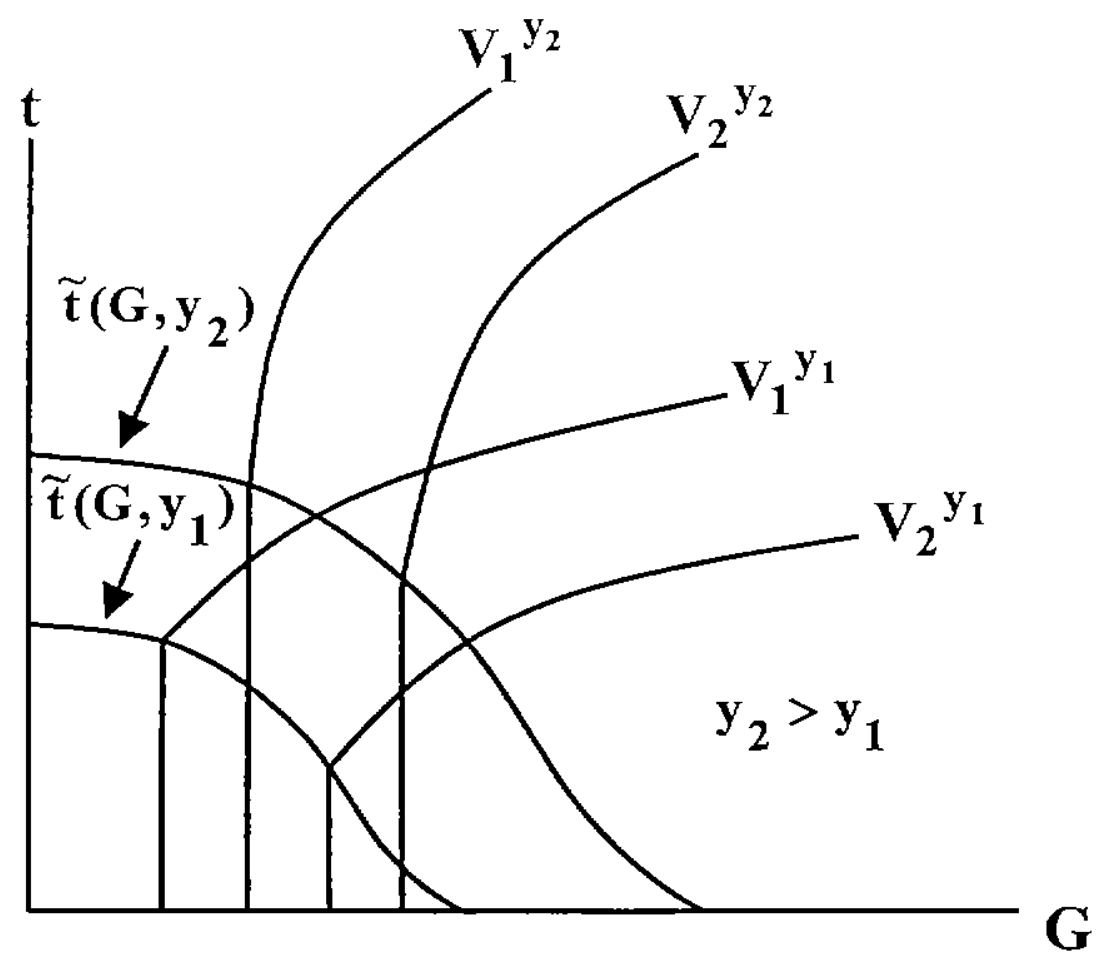

Figure 2A: Preference Mappings Under SRI

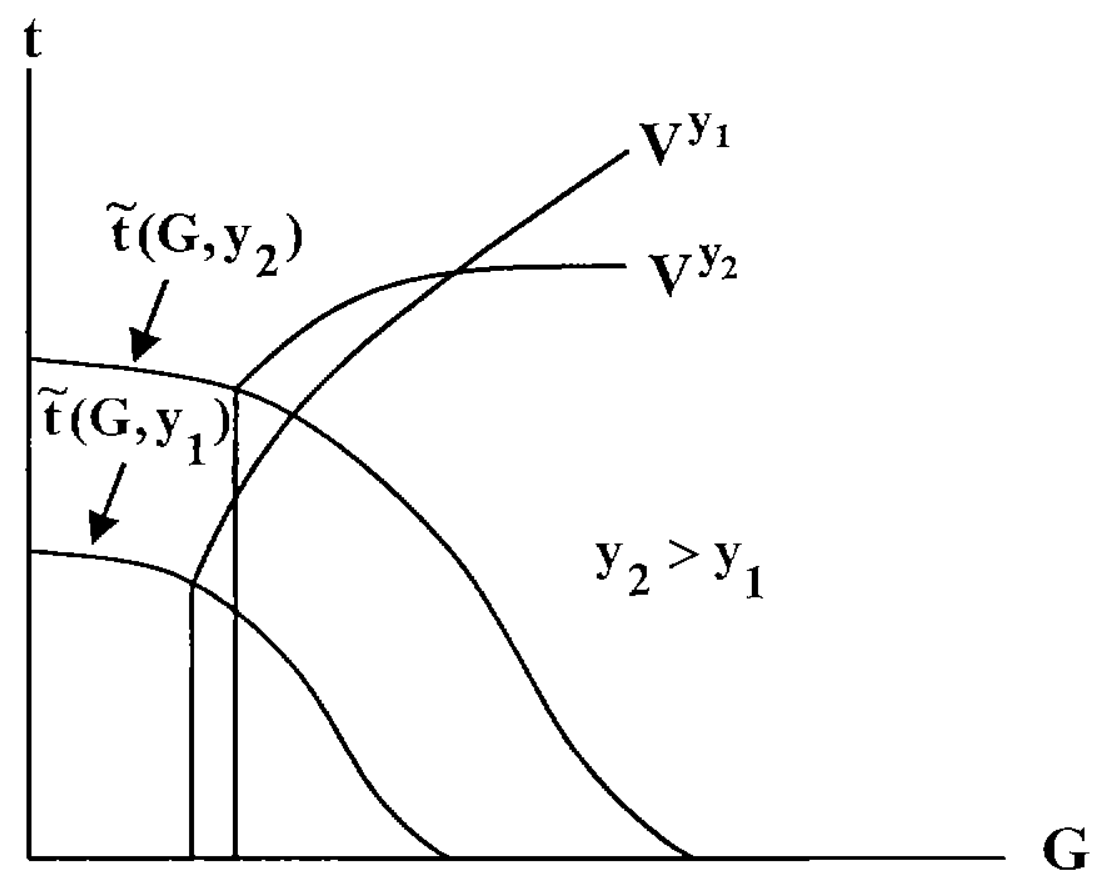

Figure 2B: Preference Mappings Under SDI 


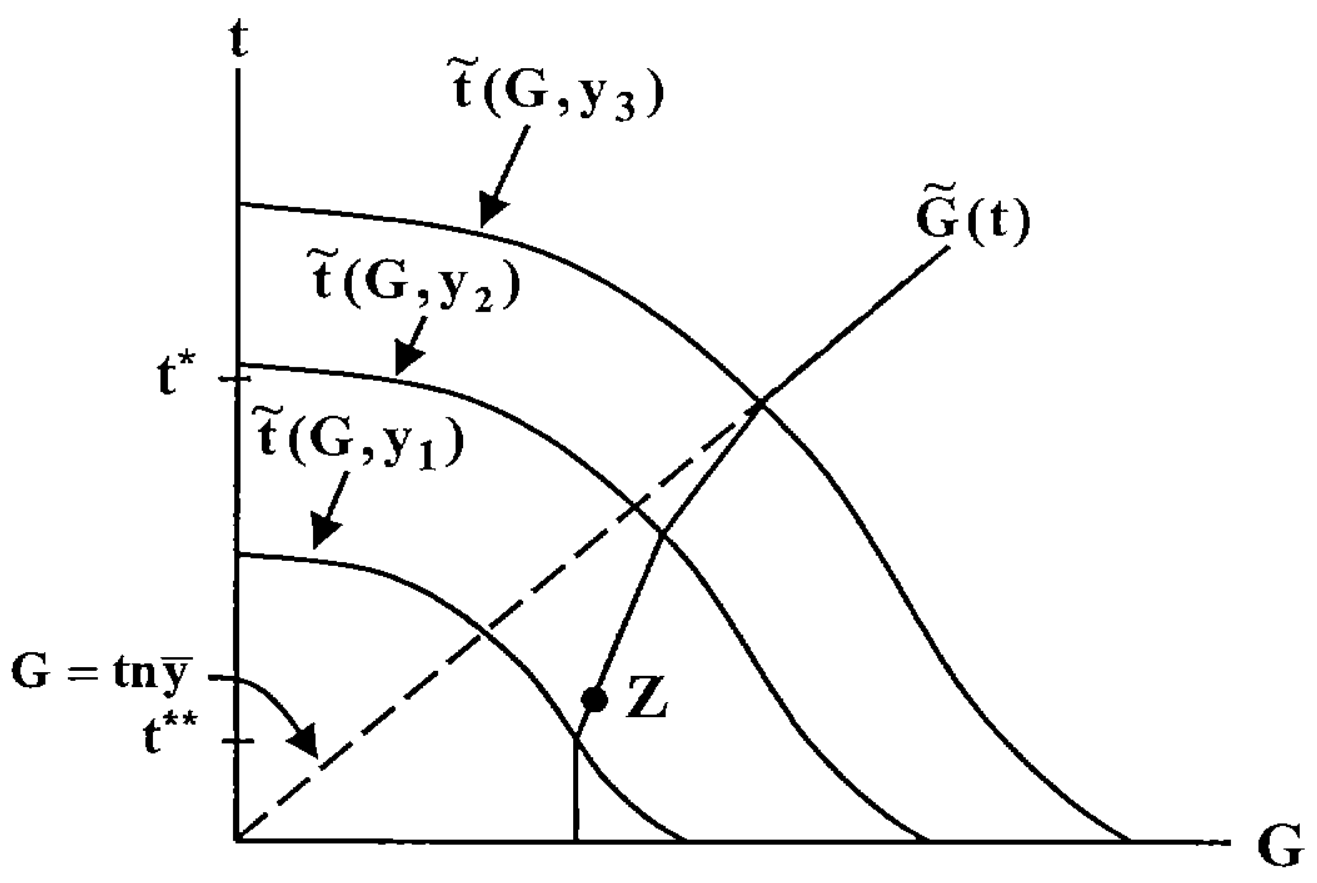

Figure 3A

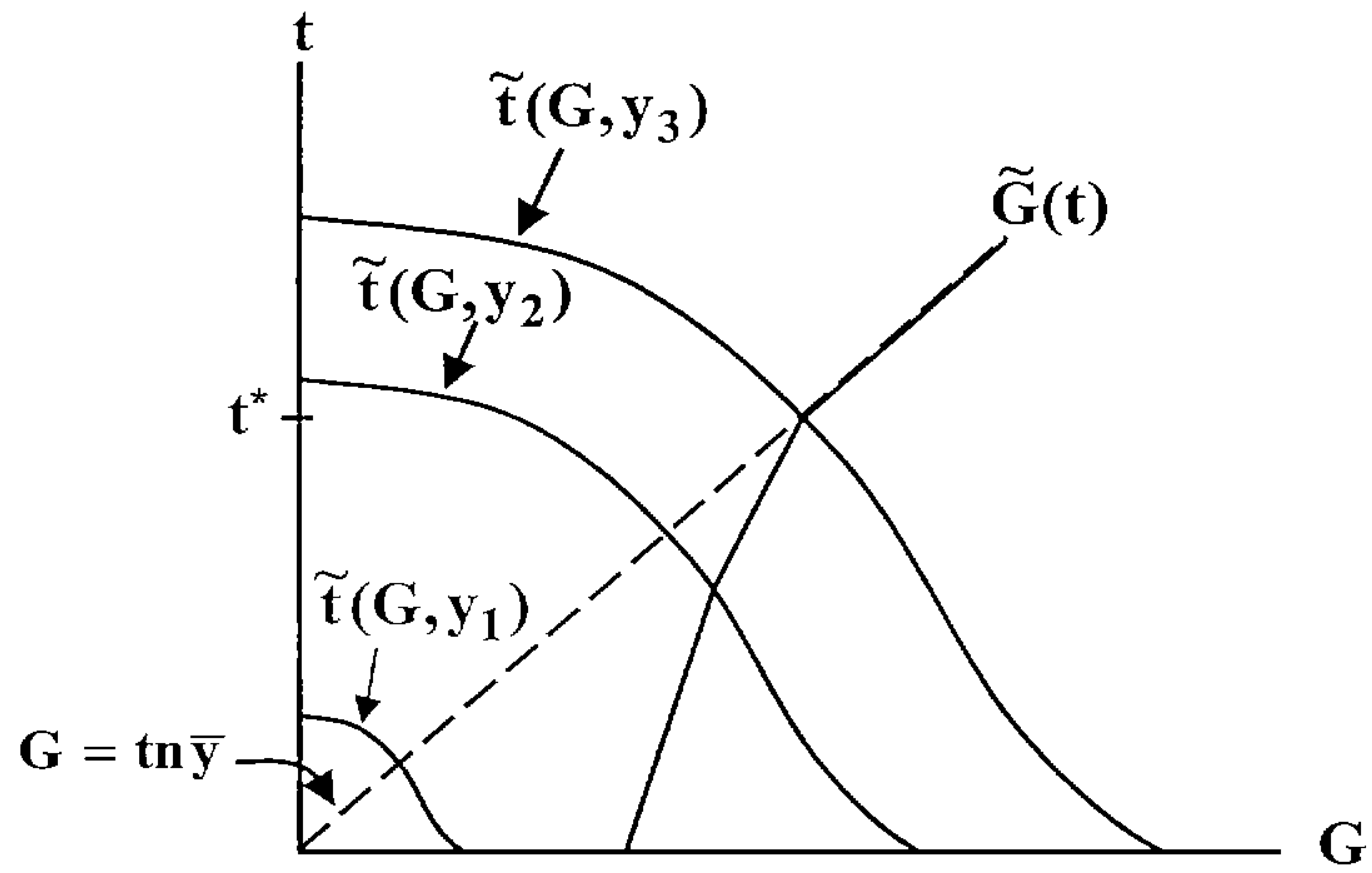

Figure 3B 


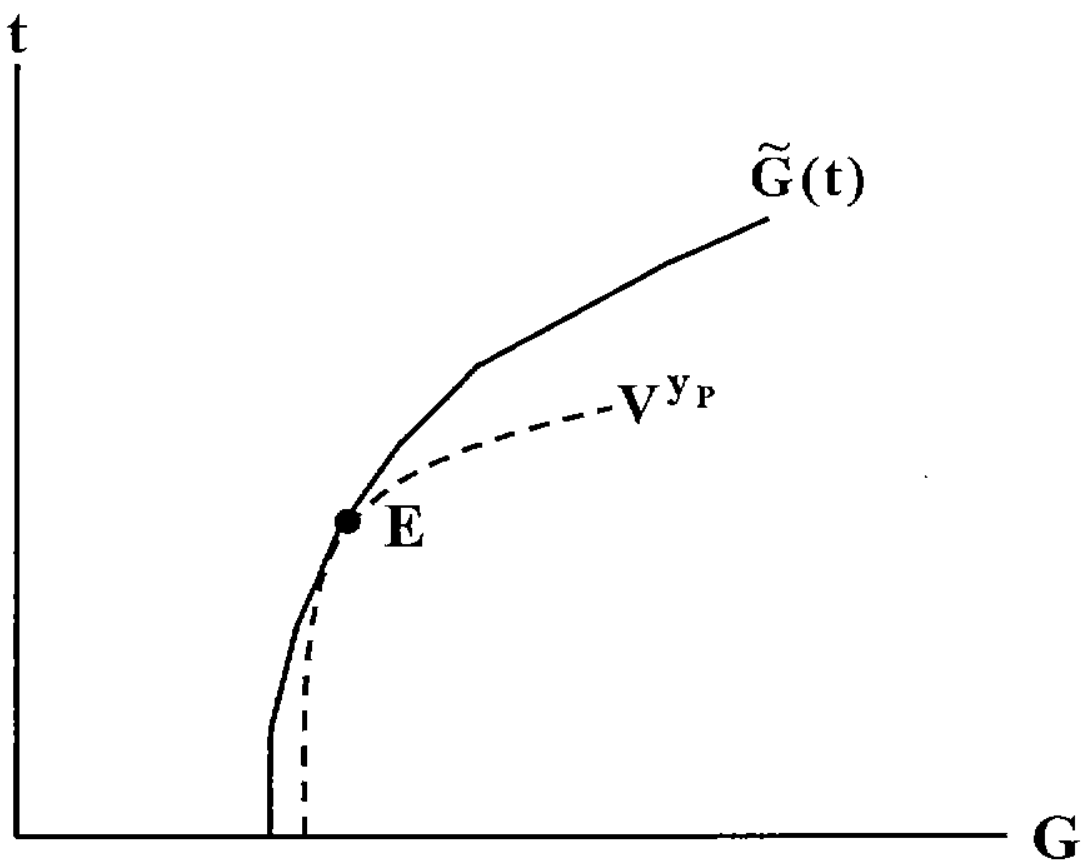

Figure 4A

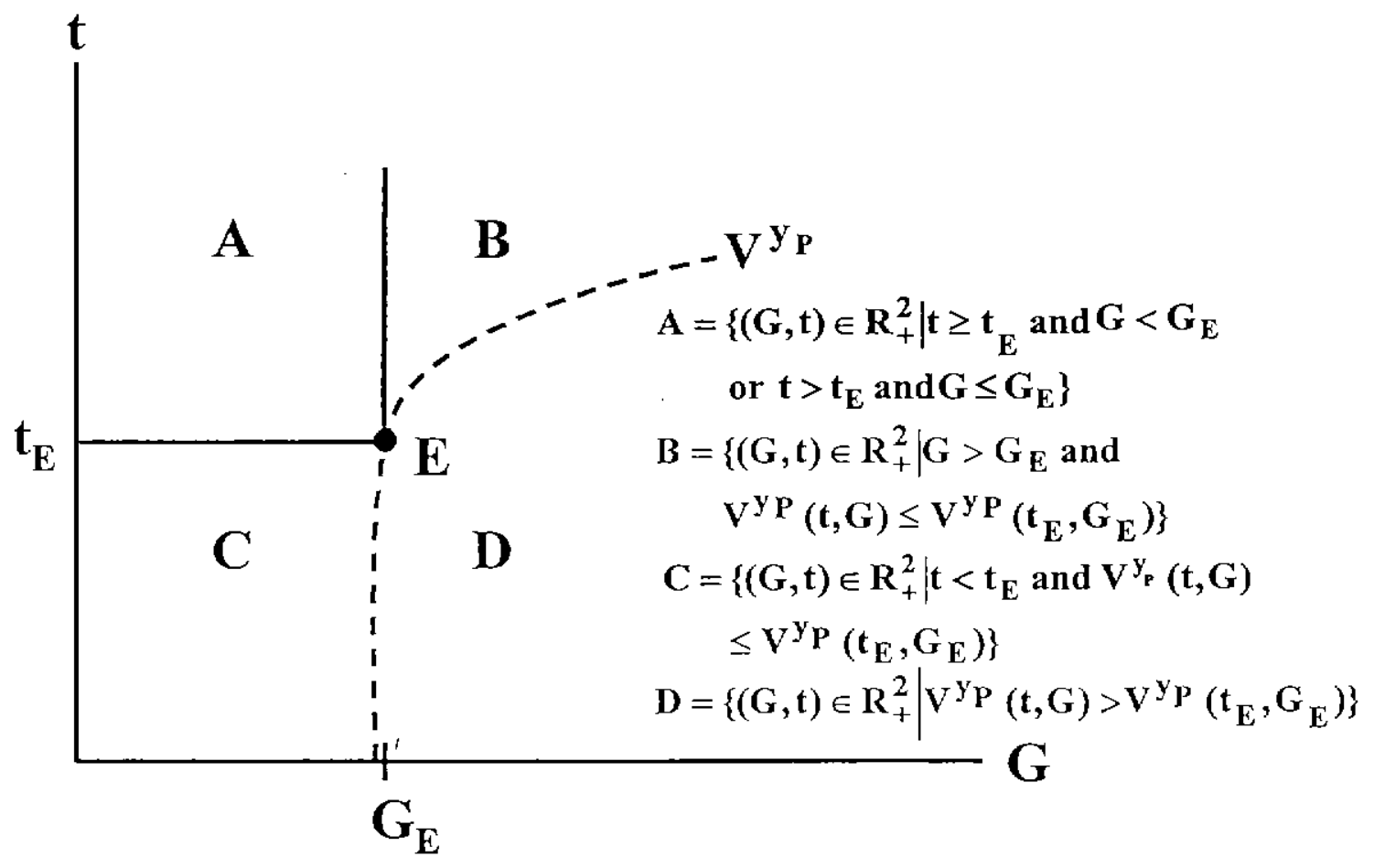

Figure 4B 
Figure 5A:

VARIATION IN PUBLIC GOOD LEVELS AS

ELASTICITY OF SUBSTITUTION VARIES

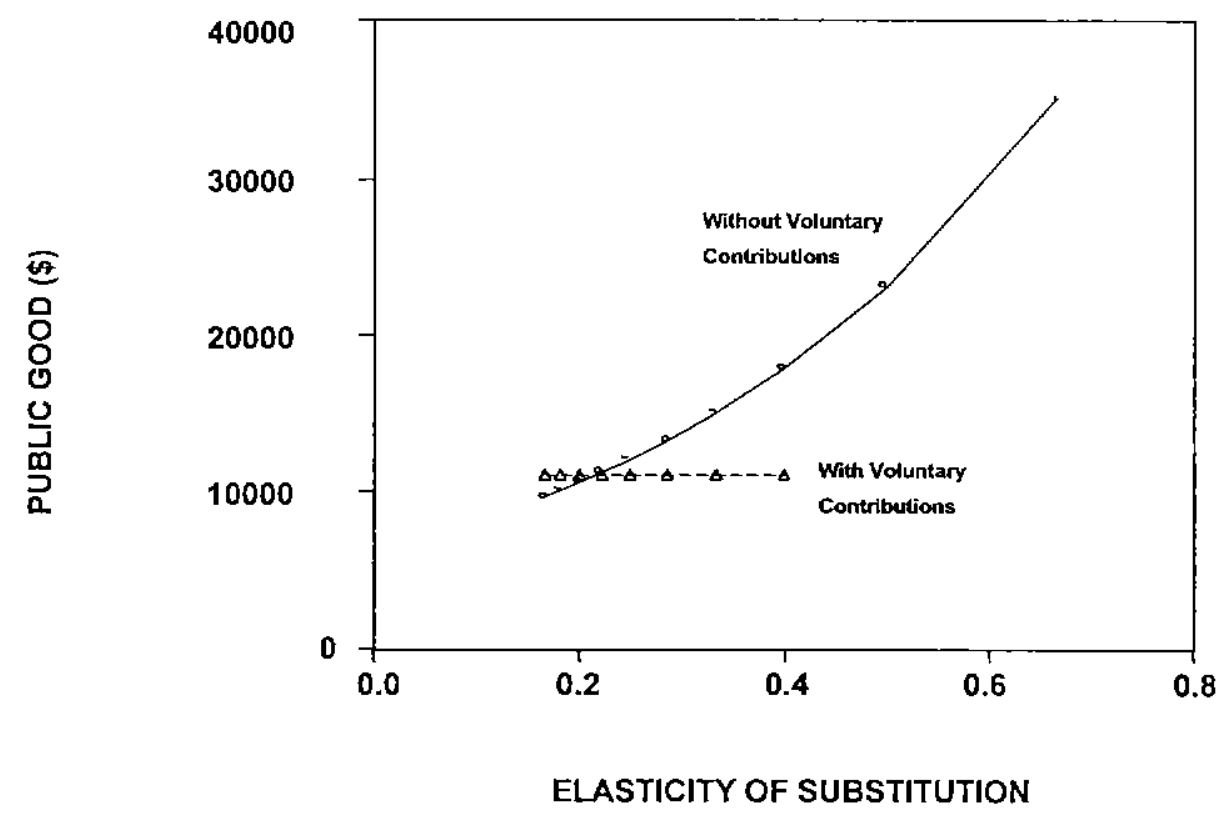

Figure 5B:

VARIATION IN PUBLIC GOOD LEVELS AS

ELASTICITY OF SUBSTITUTION VARIES

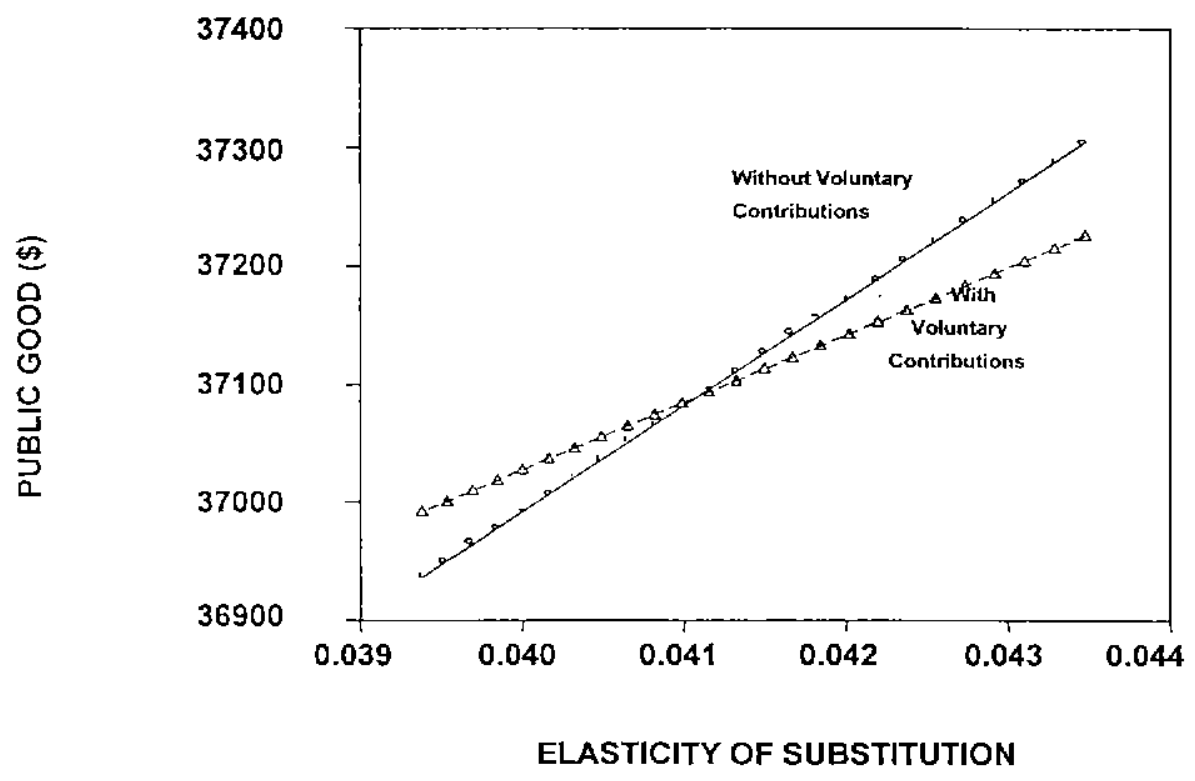




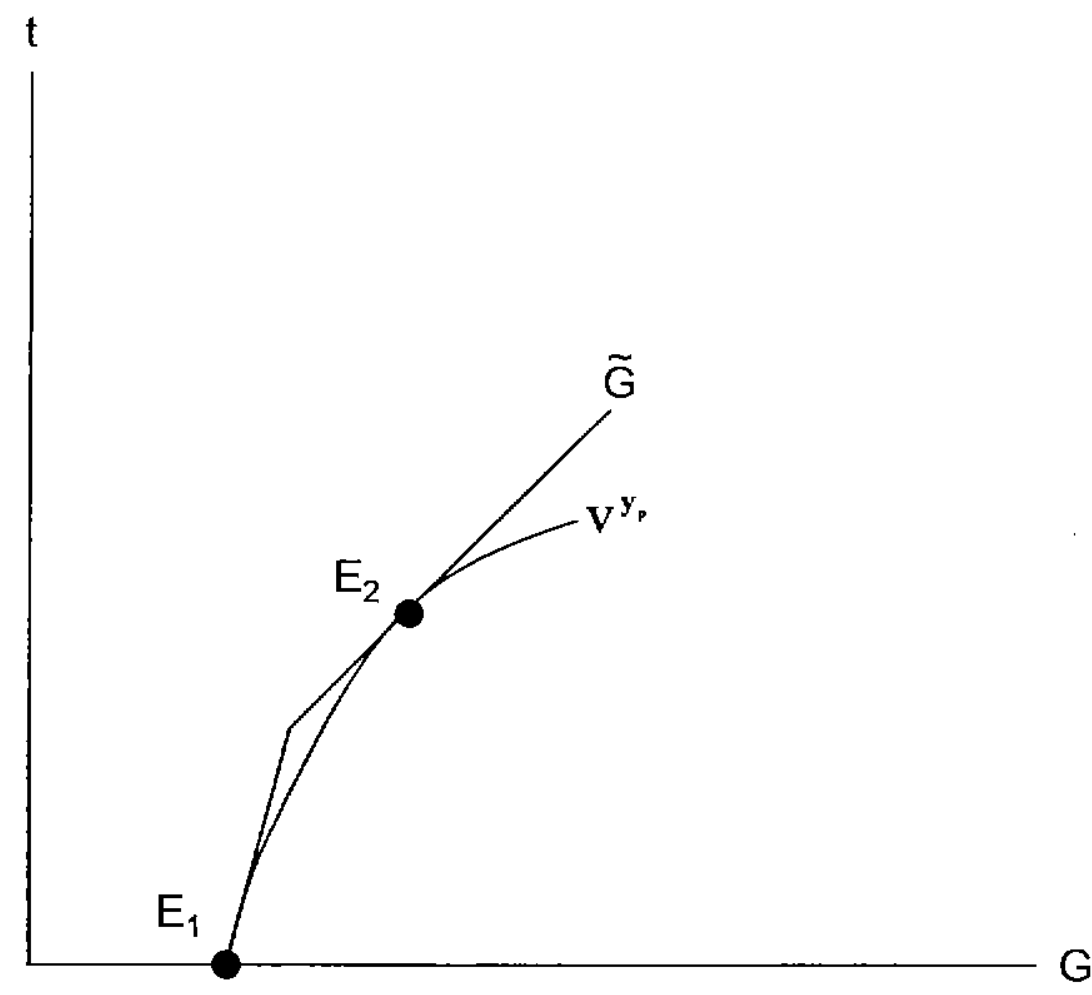

Figure 6A

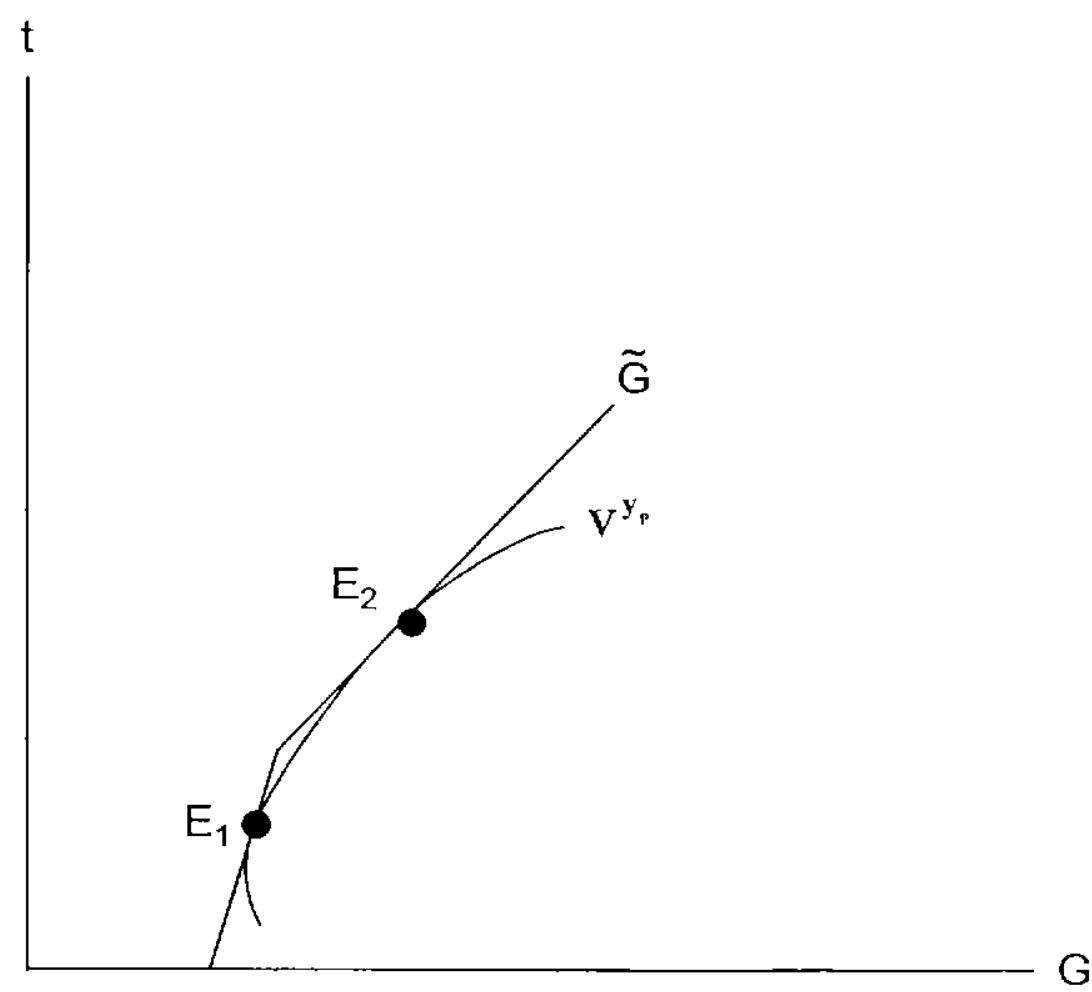

Figure 6B 
Figure 7:

CHANGE IN PUBLIC GOOD LEVEL AS NUMBER OF HIGH-INCOME INDIVIDUALS IS INCREASED

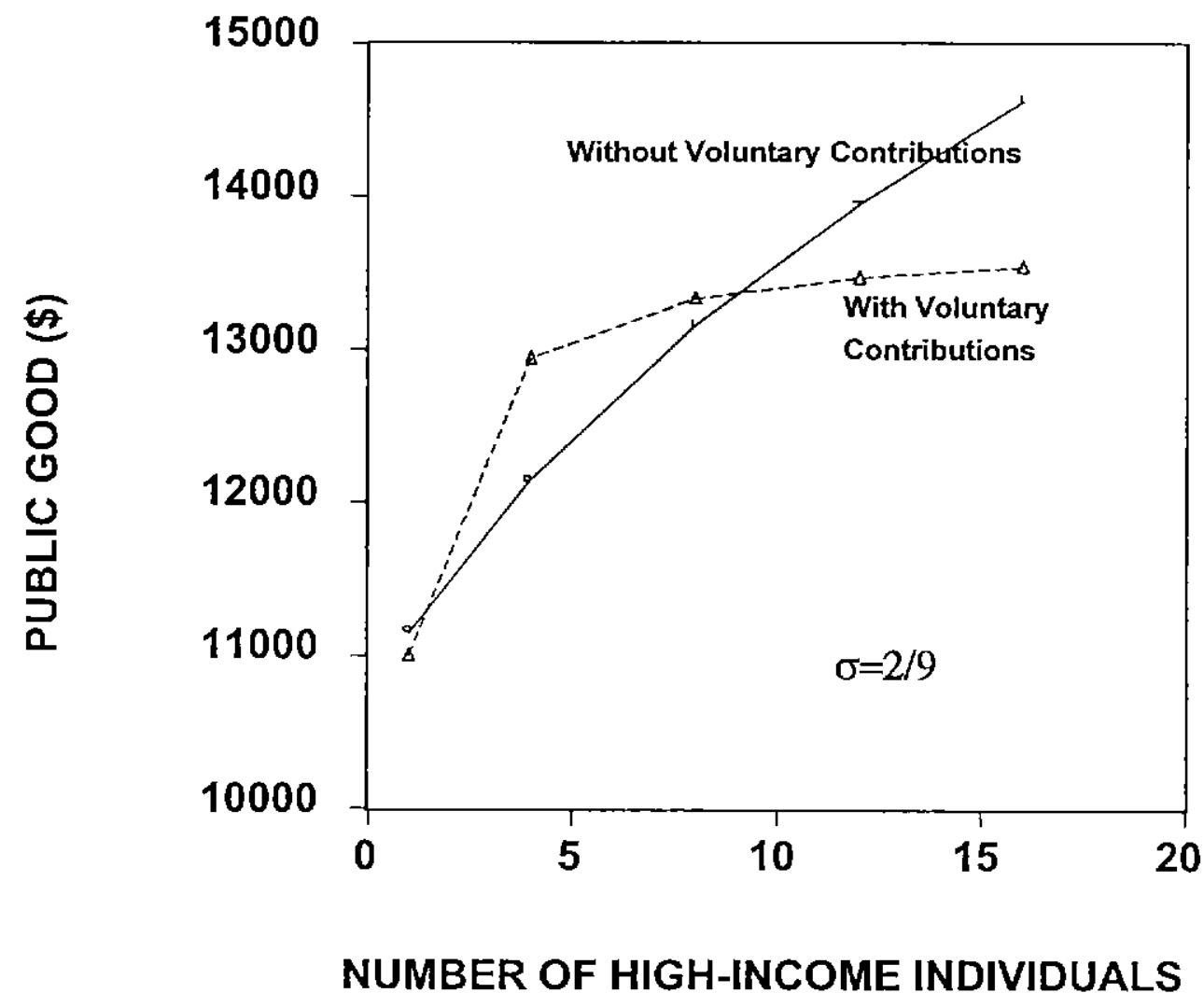


Figure 8:

COMPARISON OF PUBLIC GOOD LEVELS WITH AND WITHOUT VOLUNTARY CONTRIBUTIONS AS POPULATION IS INCREASED

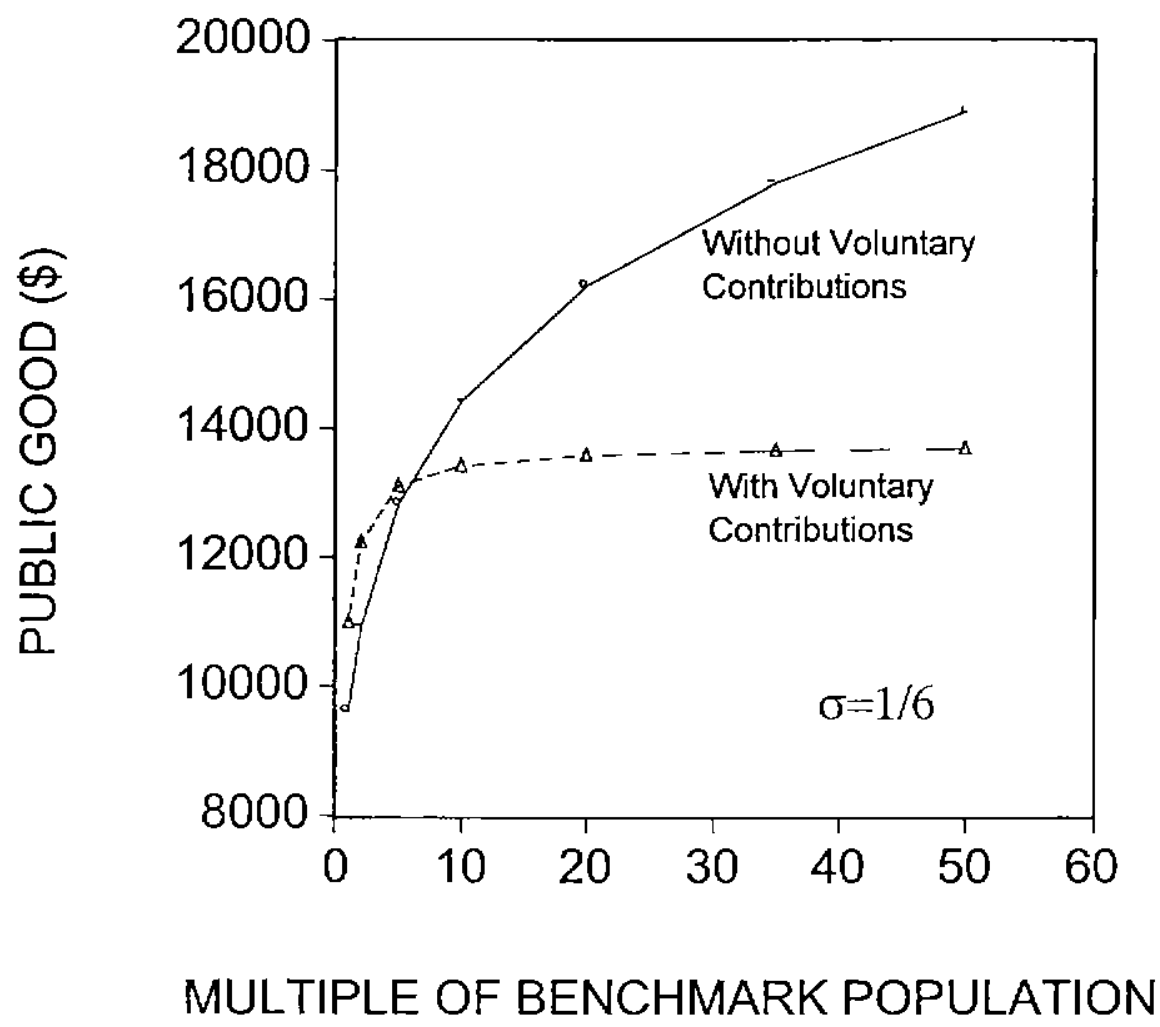


Figure 9:

TAX RATE AS FUNCTION OF INCOME OF PIVOTAL VOTER

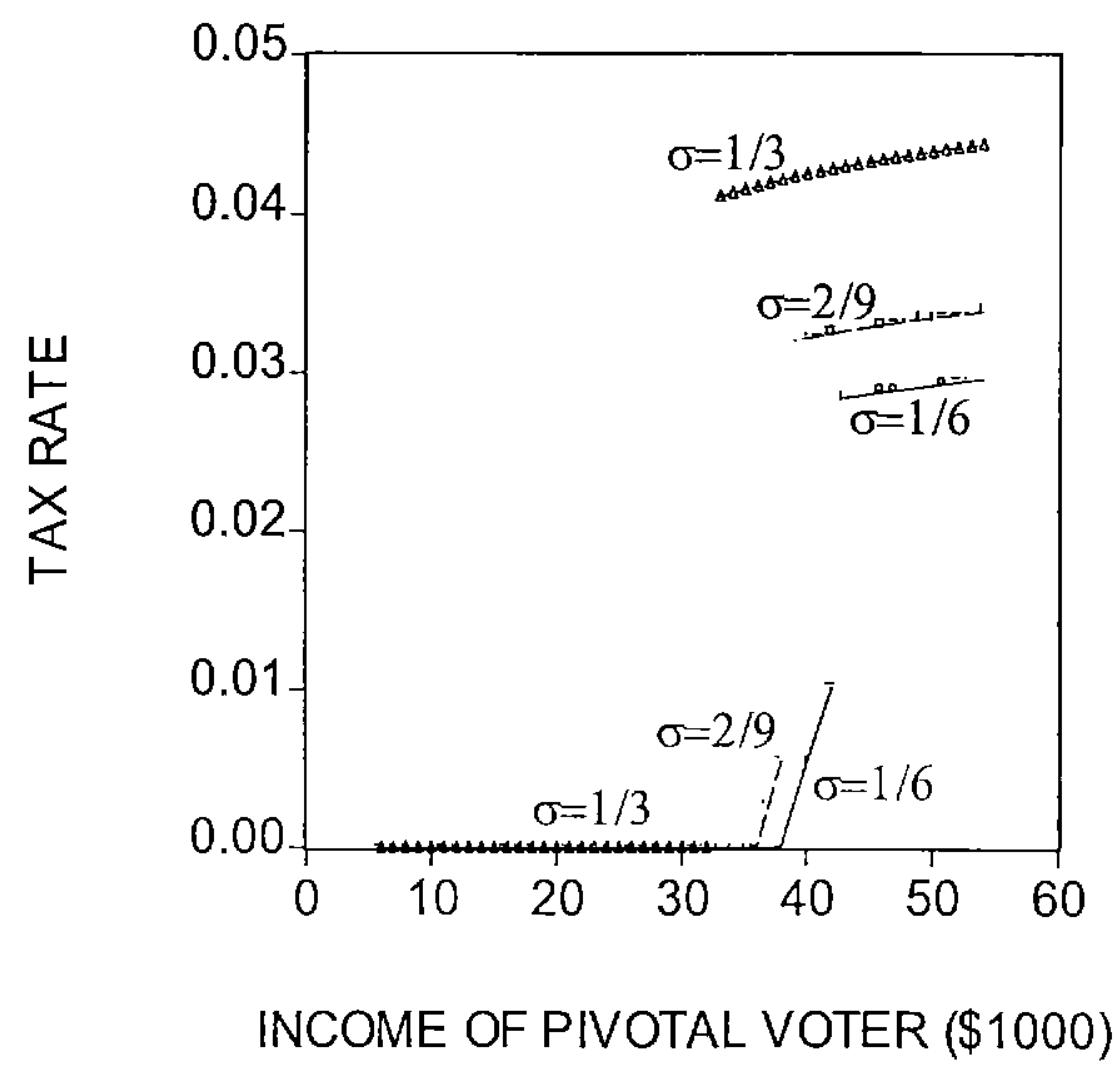




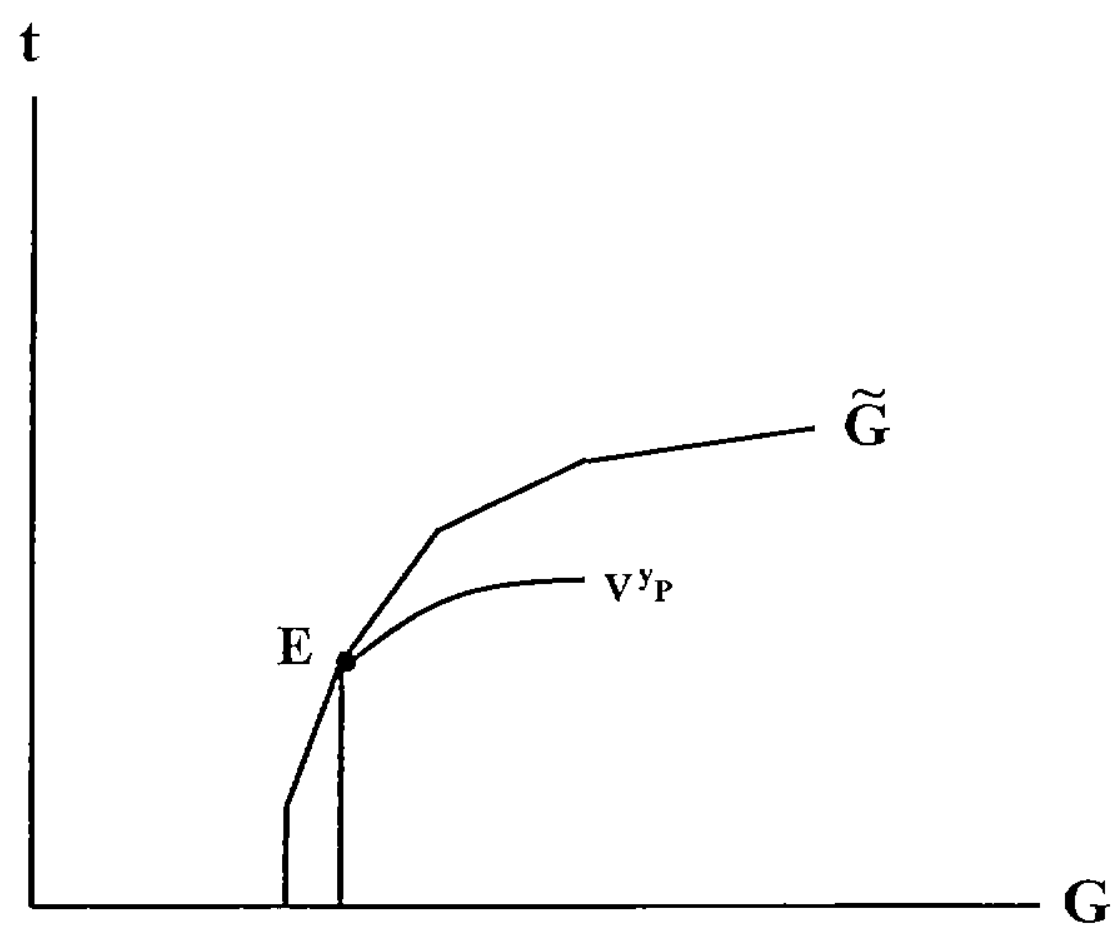

Figure A.1

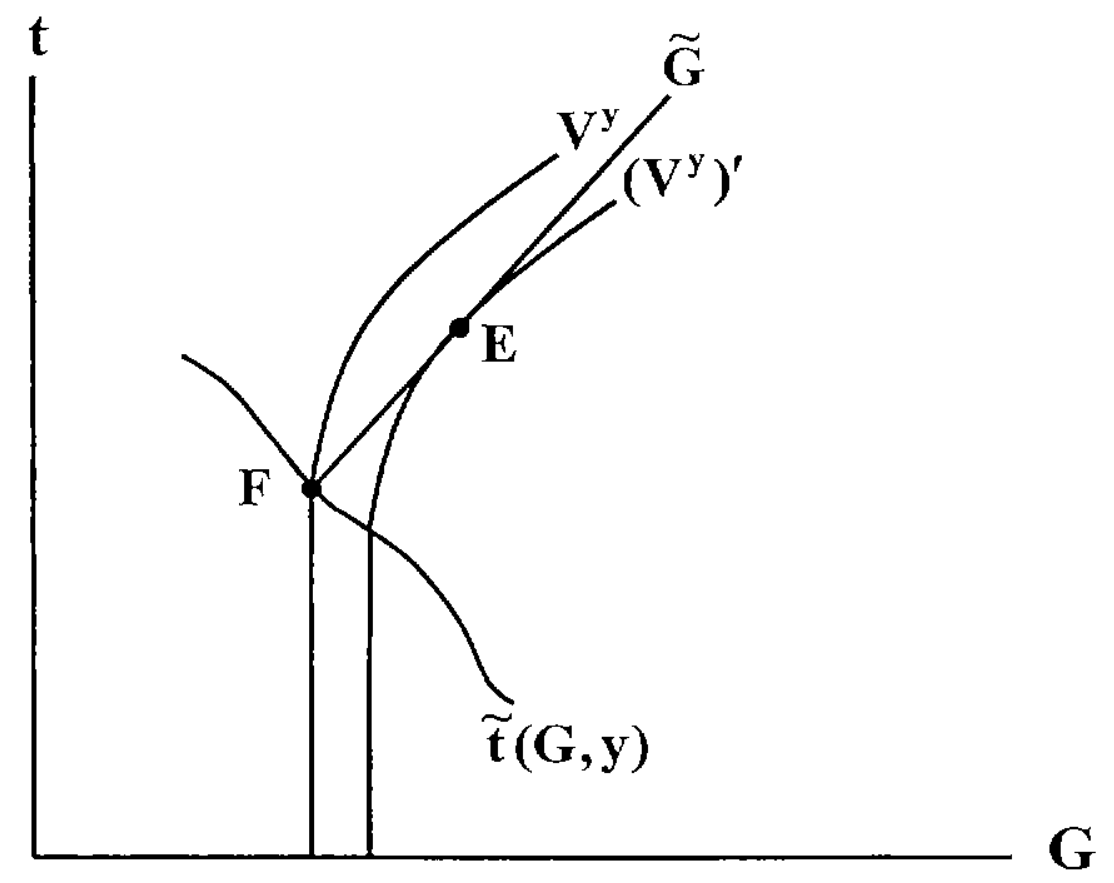

Figure A.2 
Excludable:

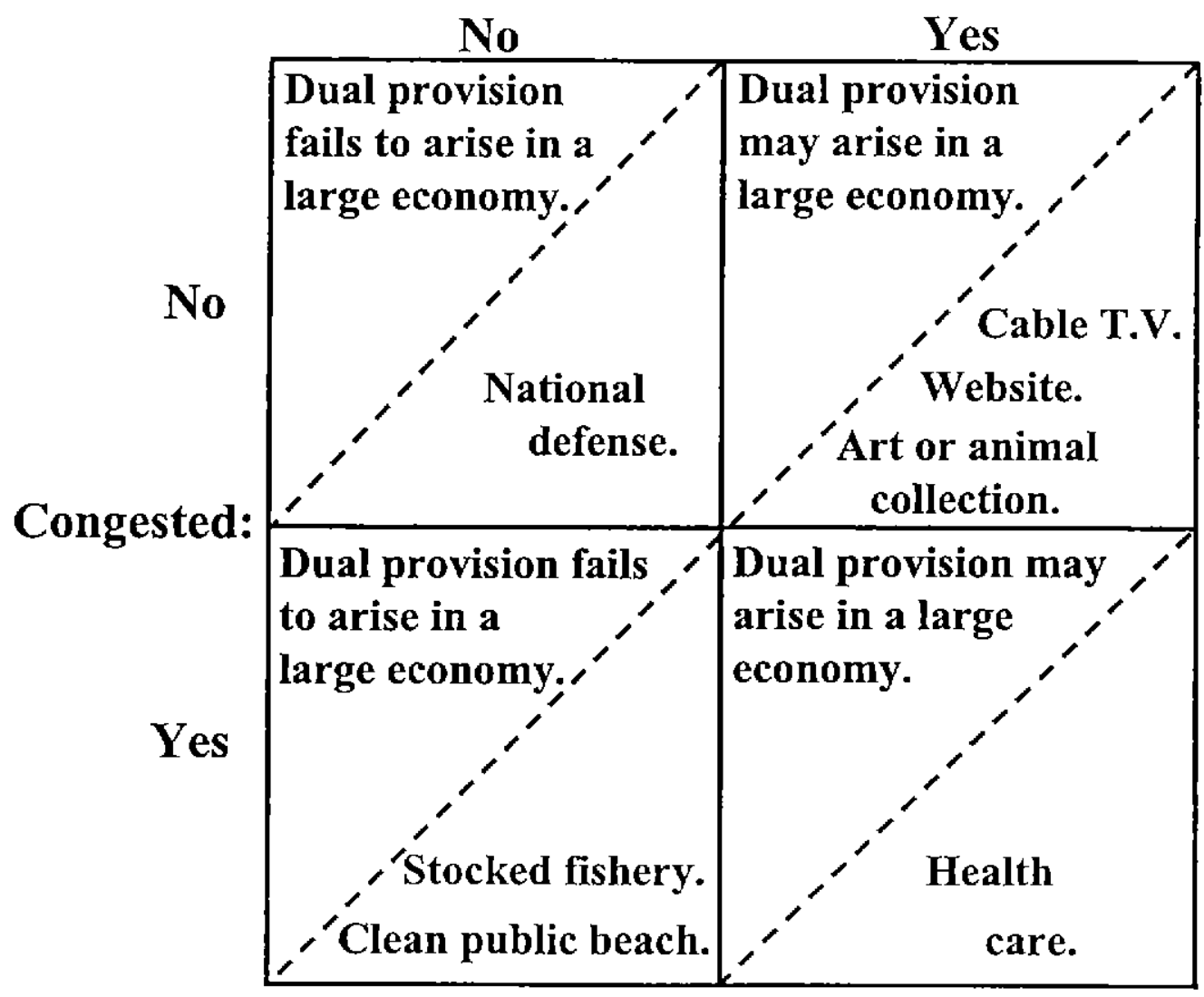

Table 1 